\title{
High temperature effects on Pi54 conferred resistance to Magnaporthe oryzae in two genetic backgrounds of Oryza sativa
}

Geoffrey Onaga ${ }^{\text {ac,*}, \text { Kerstin Wydra }}{ }^{\mathrm{b}}$, Birger Koopmann ${ }^{\mathrm{a}}$, Dmytro Chebotarov ${ }^{\mathrm{c}}$, Yakouba Séréd, and Andreas Von Tiedemann ${ }^{\mathrm{a}}$

${ }^{a}$ Division of Plant Pathology and Crop Protection, Department of Crop Sciences, Georg-AugustUniversity Göttingen, Germany

${ }^{b}$ Erfurt University of Applied Sciences, Horticulture - Plant Production and Climate Change, Leipziger Str. 77, 90085 Erfurt, Germany;

${ }^{c}$ International Rice Research Institute (IRRI), DAPO Box 7777, Metro Manila, Philippines

${ }^{d}$ Africa Rice Center, P.O Box 33581, Dar es Salaam, Tanzania.

*Correspondence: Email: gonaga@gwdg.de

\section{ABSTRACT}

The global temperatures are predicted to rise due to climate change. However, knowledge on the mechanisms underlying the effect of high temperature (HT) on plant pathogen interaction is limited. We investigated the effect of elevated temperature on host phenotypic, biochemical and gene expression patterns in the rice-Magnaporthe oryzae (Mo) pathosystem using two genetic backgrounds, Co39 (Oryzae sativa-indica) and LTH (O. sativa-japonica) with (CO and LT) and without (Co39 and LTH) R gene (Pi54). After exposure to $28^{\circ} \mathrm{C}$ and $35^{\circ} \mathrm{C}$ the two genetic backgrounds showed contrasting responses to Mo. At $28^{\circ} \mathrm{C}, \mathrm{CO}, \mathrm{Co} 39$ and $\mathrm{LTH}$ displayed a more severe disease phenotype than LT. Surprisingly, CO became resistant to Mo after exposure to $35^{\circ} \mathrm{C}$. $\mathrm{CO}$ and LT were used for further analysis to determine the defence related biochemical and transcriptome changes associated with HT induced resistance, and the contrasting reactions to Mo observed in $\mathrm{CO}$ and LT despite carrying the same R gene. Preexposure to $35^{\circ} \mathrm{C}$ triggered intense callose deposits and cell wall fluorescence of the attacked epidermal cells, as well as, increased hydrogen peroxide $\left(\mathrm{H}_{2} \mathrm{O}_{2}\right)$ and salicylic acid (SA) levels. On the other hand, transcriptional changes due to combined stress $\left(35^{\circ} \mathrm{C}+\mathrm{Mo}\right)$ were largely overridden by pathogen infection in both backgrounds, suggesting that the plants tended to shift their response to the pathogen. However, significant differences in global gene expression patterns occurred between $\mathrm{CO}$ and LT backgrounds in response to both single $\left(35^{\circ} \mathrm{C}\right.$ and $\left.\mathrm{Mo}\right)$ and double stress $\left(35^{\circ} \mathrm{C}+\mathrm{Mo}\right)$. Collectively, our results suggest that rice lines carrying Pi54 respond to Mo by rapid induction of callose and $\mathrm{H}_{2} \mathrm{O}_{2}$, and that these resistance mechanisms are amplified at HT. The relative difference in disease severity between $\mathrm{CO}$ and $\mathrm{LT}$ at $28^{\circ} \mathrm{C}$ suggests that the genetic background of japonica rice facilitates the function of Pi54 more than the background of indica rice. The phenotypic plasticity and gene expression differences between $\mathrm{CO}$ and LT backgrounds reveal the presence of intricate molecular signatures that may potentially influence adaptation to plant stresses.

Keywords: Genetic background, R genes, climate change, rice, Magnaporthe oryzae 


\section{Introduction}

Global climate models project an increase in average global temperatures by 2 to $5^{\circ} \mathrm{C}$ until the end of the $21^{\text {st }}$ century (Bokszczanin and Fragkostefanakis, 2013). This increase in temperature is predicted to constrain crop productivity in various ways, including alterations in the biology of plants and their interaction with pathogens. In Africa and in other tropical and sub-tropical countries, the rice crop is already exposed to some episodes of high temperatures $\left(35^{\circ} \mathrm{C}\right.$ or higher), often in combination with pathogen infections. Thus, insights on how plants respond to elevated temperature and other stresses simultaneously are crucial research tasks in practical management of plant production. Such insights will be relevant to plant breeding and pathology, and would provide tools for further understanding of cross talk between biotic and abiotic stress responses.

Many regulatory pathways and networks are activated in plants when temperature and pathogen stresses occur simultaneously, but may function antagonistically, synergistically or unrelated due to high specificity of hostpathogen interactions. Therefore, the precise mechanism of crosstalk between high temperature (HT) and pathogen stress is controversial, and outlines challenges posed by climatic factors on host-pathogen interaction. In light of increased pathogen infections, it has been demonstrated that some pathosystems already bear the brunt of increasing temperatures. For instance, HT suppressed the resistance of wheat to Puccinia graminis tritici (Harder et al., 1979) and the resistance of soybean to Phytophthora sojae (Gijzen et al., 1996). In addition, the $N$ gene of tobacco that confers resistance to tobacco mosaic virus at $22^{\circ} \mathrm{C}$ was shown to break down at $30^{\circ} \mathrm{C}$ (Whitham et al., 1996). Likewise, the amount of EDS1 and PAD4 transcripts was reported to be temperature dependent in Arabidopsis, with lower accumulation at $28^{\circ} \mathrm{C}$ than at $22^{\circ} \mathrm{C}$ (Yang and Hua, 2004). Moreover, the hypersensitive response conferred by Arabidopsis $R P W 8$ gene against powdery mildew was shown to be suppressed at temperatures above $30^{\circ} \mathrm{C}$ (Xiao et al., 2003).

Conversely, the yellow rust resistance gene Yr36 was reported to be up-regulated at HT, leading to full or partial resistance against stripe rust (Puccinia striiformis) in spring wheat (Fu et al., 2009). High temperature also positively modulated $\mathrm{Xa}$ and $\mathrm{Rp1-D21}$ mediated resistance in rice (Webb et al., 2010) and maize (Negeri et al., 2013), respectively. Thus, plant response to both HT and pathogen stress, when occurring simultaneously, can be varied in multiple ways, and indicates the delicate balance between the components that influence disease development in a pathosystem.

Alternatively, the genetic background appears to affect the effectiveness of $\mathrm{R}$ genes, and may modulate differently the global expression of genes following pathogen infection (Palloix et al., 2009). For instance, a study involving transgenic rice plants carrying Xa26 (also known as Xa3) found that the background of japonica variety, Mudanjiang 8, was more resistant to Xanthomonas oryzae pv. Oryzae (Xoo) strains than the gene donor, indica variety Minghui 63 (Sun et al., 2004; Cao et al., 2007). Similar findings were reported in 
Arabidopsis, in which the function of an allele of Arabidopsis $R$ gene RPS 2 was found to be influenced by the genetic background (Banerjee et al., 2001).

Collectively, these findings indicate a potential complexity associated with HT, genetic background and R gene mediated resistance in plants against pathogens. Thus, a comparison of phenotypic and transcriptome expression between genetic backgrounds in response to pathogens at elevated temperature could be interesting.

Magnaporthe oryzae (Mo) is the most destructive pathogen of rice, a staple crop for over half of the world's population (Xue et al., 2012). The primary breeding tool in rice blast management is to introduce resistance (R) genes into elite rice cultivars. During the past 25 years, genetic and molecular analysis of resistant donors has led to identification and mapping of more than 100 major blast resistance $(\mathrm{R})$ genes; 22 of these genes have been cloned and used for crop protection against Mo (Zhang et al., 2015). Several of these R genes have also been used for developing independent sets of near-isogenic lines (NILs) in both $O$. japonica and $O$. indica backgrounds, some of which confer broad-spectrum resistance against Mo strains tested under normal growth conditions (Liu et al., 2002; Jiang et al., 2012b; Onaga and Asea, 2015). However, the potential of rice and the introgressed R genes to adapt to both HT and Mo stresses remains less studied. Thus, it is important to gain in-depth knowledge about the complexity of phenotypic, biochemical and transcriptional changes that occur in $O$. japonica and $O$. indica genetic backgrounds, introgressed with $\mathrm{R}$ genes, in response to Mo at elevated temperature. This will provide insights on how combined abiotic and biotic stresses, as influenced by the genetic background, can alter plant productivity.

In this study, we used two rice genetic backgrounds, Co39 and LTH, with and without Pi54, to examine the response of rice to HT and Mo at elevated temperature. Pi54 possesses a nucleotide binding site-leucine rich repeat (NBS-LRR) in addition to a small zinc finger domain, and was previously reported to be constitutively expressed at basal levels in both resistant transgenic as well as susceptible rice lines up to 48 hpi (Gupta et al., 2012). We show that rice lines carrying Pi54 respond to Mo by rapid induction of callose and $\mathrm{H}_{2} \mathrm{O}_{2}$, and that these resistance mechanisms are amplified at HT. We also found that plants with Co39 background had a severe disease phenotype than $\mathrm{LTH}$ at $28^{\circ} \mathrm{C}$, suggesting that the genetic background plays a significant role in rice response to Mo.

\section{Results}

\subsection{Phenotypic and biochemical responses of M. oryzae infected plants before and after high temperature} exposure

The interaction between rice and Mo was investigated under normal $\left(28^{\circ} \mathrm{C}\right)$ and elevated $\left(35^{\circ} \mathrm{C}\right)$ temperature conditions, using CO, LT, Co39 and LTH. At $28^{\circ} \mathrm{C}, \mathrm{CO}, \mathrm{Co} 39$ and LTH had a severe disease phenotype and 
displayed lesions within 5 days post inoculation (dpi), while LT exhibited reduced lesion sizes (Fig. 1A). At $35^{\circ} \mathrm{C}$, Pi54 associated lesion development was rarely observed on both NILs. To exempt any direct effect of HT on the pathogen, plants were grown at $35^{\circ} \mathrm{C}$ for $7 \mathrm{~d}$ prior to Mo inoculation, where after all procedures were carried out at identical temperature conditions $\left(28^{\circ} \mathrm{C}\right)$. Pre- exposure to $35^{\circ} \mathrm{C}$ induced a delay in disease progress and typical HR lesions in both NILs and their recurrent parental backgrounds (Co39 and LTH), although the disease progress remained comparatively higher in the recurrent parents (Fig. 1B).

To further investigate HT modulation of plant defence, $\mathrm{CO}$ and LT were used for further analysis to determine the biochemical and transcriptome changes associated with HT induced resistance. The levels of callose deposition and $\mathrm{H}_{2} \mathrm{O}_{2}$ in $\mathrm{CO}$ and LT plants pre-exposed to $35^{\circ} \mathrm{C}$ and inoculated with Mo was compared with that in plants grown and inoculated at $28^{\circ} \mathrm{C}$. Plants pre-exposure to $35^{\circ} \mathrm{C}$ followed by Mo inoculation showed intense callose accumulation as well as cell wall fluorescence of the attacked epidermal cells in both NILs (Fig. 2). In accordance with callose deposition, both NILs had significantly higher $\mathrm{H}_{2} \mathrm{O}_{2}$ levels in plants pre-exposed to $35^{\circ} \mathrm{C}$ and $\mathrm{Mo}$ (Fig. 3A). However, $\mathrm{H}_{2} \mathrm{O}_{2}$ activity declined significantly in $\mathrm{CO}$ plants exposed to $28^{\circ} \mathrm{C}$ and $\mathrm{Mo}$ at 48 hpi. Exposure to HT also increased peroxidase (POX) activity in both NILs (Fig. 3B). However, in spite of showing consistently higher activity at $48 \mathrm{hpi}$, POX activity was not significantly different between CO plants pre-exposed to $28^{\circ} \mathrm{C}$ and $35^{\circ} \mathrm{C}$ prior to Mo inoculation at $24 \mathrm{hpi}$. We also found significantly lower POX activity in LT plants infected with Mo at 48 hpi despite showing higher induction at 24 hpi.

The phenolic phytohormone, salicylic acid (SA), has beneficial effects on plant growth and development under stress conditions (Awasthi et al., 2015). We compared the levels of SA in plants exposed to $35^{\circ} \mathrm{C}$ and Mo using $\mathrm{CO}$ and LT NILs. HT induced significant increases in free SA in both NILs prior to Mo inoculation (Fig. 4A). Alternatively, for plants exposed to Mo, we found consistently higher levels of free SA in CO than LT, regardless of the temperature difference. However, at $48 \mathrm{hpi}$, plants pre-exposed to $35^{\circ} \mathrm{C}$ had a significant reduction in SA in both NILs; although SA remained comparatively higher in CO than LT. In contrast to SA levels, LT had significantly higher PAL activity at 24 hpi than $\mathrm{CO}$ in plants inoculated at $28^{\circ} \mathrm{C}$ (Fig. 4B). Interestingly, preexposure to $35^{\circ} \mathrm{C}$ followed by Mo inoculation induced higher PAL activity in $\mathrm{CO}$, and this was consistently higher up to 48 hpi. Conversely, PAL activity significantly declined in LT plants exposed to $35^{\circ} \mathrm{C}$ and $\mathrm{Mo}$ at 48 hpi.

\subsection{Transcription profiles of CO and LT infected with Mo at $28^{\circ} \mathrm{C}$ and $35^{\circ} \mathrm{C}$}

To determine temperature-induced transcriptome changes, genome-wide gene expression patterns were investigated in $\mathrm{CO}$ and LT using mRNA-seq following exposure to $35^{\circ} \mathrm{C}$ and Mo. Three biological replicates of each treatment were sequenced, yielding an average of sixty nine million reads. For a global view on the sample 
relationships, principal component analysis was computed based on one third of the genes with highest variance in expression levels (Fig. S1). Principal component 1 and 2 accounted for $38 \%$ of the inherent data variance between the samples, and some of the replicates segregated distinctively for one material origin. On average, 32,000 genes were detected. Fold changes were calculated for the genes obtained, and a false discovery rate (FDR) of 0.05 was set for the calling of differentially expressed genes (DEG). The number of DEG in plants exposed to $\mathrm{Mo}\left(\mathrm{CO}+28^{\circ} \mathrm{C}+\mathrm{Mo}, \mathrm{LT}+28^{\circ} \mathrm{C}+\mathrm{Mo}, \mathrm{CO}+35^{\circ} \mathrm{C}+\mathrm{Mo}\right.$ and $\left.\mathrm{LT}+35^{\circ} \mathrm{C}+\mathrm{Mo}\right)$ was significantly higher than in plants exposed to only $\mathrm{HT}$ stress $\left(\mathrm{CO}+35^{\circ} \mathrm{C}\right.$ and $\mathrm{LT}+35^{\circ} \mathrm{C}$; Additional file S1). A small subset of genes (600) was shared between plants exposed to HT and Mo (Additional file S2), and hierarchical clustering on the $\log _{2}$ transformed fold change values clearly showed a considerable transcript profile separation between plants exposed to HT and Mo (Fig. 5). Likewise, substantial differences were observed between gene ontology (GO) terms enriched in plants exposed to HT and Mo in both NILs (Table S1). However, most of the GO terms that were enriched in the up-regulated gene set in response to HT were similar between CO and LT (Fig. 6A, B), suggesting that LT and CO do not substantially differ in the biological processes responding to HT treatment. Oxidation-reduction process was the most enriched and common GO term identified, containing over 400 DEGs from LT and 390 from CO. Defence response to fungus, incompatible interaction (GO:0009817) was significantly enriched in $\mathrm{LT}+28^{\circ} \mathrm{C}+\mathrm{Mo}, \mathrm{LT}+35^{\circ} \mathrm{C}+\mathrm{Mo}$ and $\mathrm{CO}+35^{\circ} \mathrm{C}+\mathrm{Mo}$ but not in $\mathrm{CO}+28^{\circ} \mathrm{C}+\mathrm{Mo}$.

\subsection{Transcriptome differences between $\mathrm{CO}+35^{\circ} \mathrm{C}+\mathrm{Mo}$ and $\mathrm{CO}+28^{\circ} \mathrm{C}+\mathrm{Mo}$}

An important part of this investigation was to identify transcripts that are differentially expressed between $\mathrm{CO}+35^{\circ} \mathrm{C}+\mathrm{Mo}, \mathrm{CO}+28^{\circ} \mathrm{C}+\mathrm{Mo}$ and $\mathrm{LT}$ to provide an indication of what molecular mechanisms may be associated with resistance at HT. The HT-treated $\left(\mathrm{CO}+35^{\circ} \mathrm{C}+\mathrm{Mo}\right)$ plants were somewhat separated from $\mathrm{CO}+28^{\circ} \mathrm{C}+\mathrm{Mo}$ : with a total of $1613 \mathrm{DEG}$ specifically expressed in $\mathrm{CO}+35^{\circ} \mathrm{C}+\mathrm{Mo}$ (Additional file S3). Most of the DEG specific to $\mathrm{CO}+35^{\circ} \mathrm{C}+\mathrm{Mo}$ were related to cell-cycle regulation (e.g., MAK16; LOC_Os07g17040 and KIP1; LOC_Os07g49480), trafficking (e.g., EXO7; LOC_Os01g55799 and ABC-1 domain containing protein; LOC_Os02g56200), photosynthesis (e.g., Chloroplast ribulose-1,5-bisphosphate carboxylase/oxygenase activase; LOC_Os11g47980, carbonic anhydrase; LOC_Os01g45274, isopropylmalate dehydrogenases; LOC_Os03g45320) and carbohydrate metabolism (e.g., glycoside hydrolase; LOC_Os01g63810 and bidirectional sugar transporter SWEETIa; LOC_Os01g65880). A significant up regulation of Peptidyl-prolyl isomerases (OsFKBP65) was also detected in $\mathrm{CO}+35^{\circ} \mathrm{C}+\mathrm{Mo}$ compared to $\mathrm{CO}+28^{\circ} \mathrm{C}+\mathrm{Mo}$. Moreover, OsFKBP65 was induced in concert with heat shock factors/proteins e.g., HSFA2, HSP81-1 (HSP90), HSP70s, and several small HSPs. A total of 1391 genes expressed in $\mathrm{CO}+28^{\circ} \mathrm{C}+\mathrm{Mo}$ were suppressed in $\mathrm{CO}+35^{\circ} \mathrm{C}+\mathrm{Mo}$ (Additional file S3). 
Conceptually, the suppression of these genes suggests sensitivity to heat stress, but could otherwise suggest that some of these genes negatively play a role in rice disease resistance.

\subsection{Co-expression network analysis}

Genes often act in networks to regulate biological processes. To identify co-expression modules (clusters) within all the genes expressed, we extracted the normalized, log transformed gene expression values in each treatment $\left(\mathrm{CO}+28^{\circ} \mathrm{C}+\mathrm{Mo}, \mathrm{LT}+28^{\circ} \mathrm{C}+\mathrm{Mo}, \mathrm{CO}+35^{\circ} \mathrm{C}+\mathrm{Mo}, \mathrm{LT}+35^{\circ} \mathrm{C}+\mathrm{Mo}, \mathrm{CO}+35^{\circ} \mathrm{C}\right.$ and $\left.\mathrm{LT}+35^{\circ} \mathrm{C}\right)$ and performed Weighted Gene Co-expression Network Analysis (WGCNA). All possible pairwise correlations were calculated for all the genes expressed in all the treatments and converted into measures of connection strength by taking their absolute values and raising them to a power, $\beta$ (soft thresholding). The soft thresholding power of 6 seemed a minimal number for which $\mathrm{R}^{2}$ had a good fit (model fit >0.5) that best approximates a scale free topology of the resultant networks, and is also the default setting in WCGNA (Fig. S2). After fixing the power, genes were split into 4 blocks, and within each block we ran WCGNA clustering using topological overlap measure to determine modules of co-expressed genes (Fig. S3). Sets of genes (modules) with common expression patterns that were associated with particular treatments were identified based on the correlation between ME and treatments (Fig. 7). We identified nine modules that significantly associated with Mo infection, 5 modules associated with genetic background and 3 modules associated with HTxMo interaction ( $r \geq 0.5, P \leq 0.01)$. Although the $\mathrm{r}$ value was lower than 0.5 , module 1 correlated positively to HT and negatively to Mo infection $[\mathrm{ME}(\mathrm{HT}), r=0.46, P=0.02$; $\mathrm{ME}(\mathrm{Mo}), \mathrm{r}=-0.69, p=2 \mathrm{e}-04]$, module 7 correlated positively to Mo infection, module 27 correlated positively to genotype x Mo and negatively to HT [ME (GxMo), $r=-0.45, P=0.03$; ME (HT), $r=-0.52, P \leq 0.01]$ and module 0 correlated positively to genotype x HT x Mo [ME $(0): r=0.32, P=0.03]$.

The modules that closely associated with treatments might be very useful for understanding the biological processes associated with these treatments. Module 7 genes are mainly involved in signal transduction (GO:0007165), defence response to bacterium (GO:0042742) and nucleobase-containing compound metabolic process (GO:0006139). Module 1, which significantly associated with HT, had its genes significantly enriched in translation regulator activity (GO:0045182), cellular aromatic compound metabolic process (GO:0006725), nitrogen compound metabolic process (GO:0046482), calcium ion binding (GO:0005509), ATPase activity, coupled to transmembrane movement of substances (GO:0042626) and signal transduction (GO:0007165).

Modules 15 and 25 were apparently the only consensus co-expression modules identified but also with weak positive association with all the traits. Module 15 genes are mainly involved in DNA binding, regulation of gene expression and RNA metabolic process, whereas module 25 genes are mainly involved in transition metal ion binding and cation binding. Module 13 was significantly associated with the genetic background, and had its 
genes significantly enriched in cell cycle, O-acyltransferase activity, S-adenosylmethionamine biosynthetic process, adenosylmethionine decarboxylase activity and DNA metabolic process.

To determine genes that are centrally located in the modules associated with treatments, we calculated the intramodular connectivity for each gene by summing the connection strengths with other module genes and dividing this number by the maximum intramodular connectivity. Genes with high intramodular connectivity are referred to as hub genes. The hub genes in the 35 modules were listed in Table S2. These hub genes may provide signature targets for further analysis, and we propose them as potential candidates for stress response in rice.

\subsection{Identification and classification of DEG contributing to resistance in $L T$ and $C O+35^{\circ} \mathrm{C}+\mathrm{Mo}$}

We categorized the DEG into six classes according to function. Class 1 included reactive oxygen species (ROS) production and antioxidant encoding genes, Class II are hormone production and signaling genes, class III are resistance $(\mathrm{R})$ genes, receptor kinases, calcium and MAPK signalling genes, class IV includes transcription factors, class V are energy and metabolism genes, and class VI are effector proteins which include defence-related proteins and enzymes involved in secondary metabolism.

In class I, the ROS production genes OsNox9 (LOC_Os12g35610) and RbohD (LOC_Os10g40020) were significantly induced ( $>5$-fold) in $\mathrm{CO}+35^{\circ} \mathrm{C}+\mathrm{Mo}, \mathrm{LT}+35^{\circ} \mathrm{C}+\mathrm{Mo}$ and $\mathrm{LT}+28^{\circ} \mathrm{C}+\mathrm{Mo}$ but not in $\mathrm{CO}+28^{\circ} \mathrm{C}+\mathrm{Mo}$ (additional file S3). Genes encoding for POX51 (LOC_Os03g55410), POX6 (LOC_Os07g02440), ferredoxin (LOC_Os03g48040), prx117 (LOC_Os08g02110) and TRX-1 (LOC_Os04g44830) were also more induced in $\mathrm{CO}+35^{\circ} \mathrm{C}+\mathrm{Mo}$ than $\mathrm{CO}+28^{\circ} \mathrm{C}+\mathrm{Mo}$. On the other hand, class II peroxidase encoding genes, e.g., prx62 (LOC_Os04g59200), genes encoding for ferrodoxins (e.g., LOC_Os07g30670 and LOC_Os03g45710), and APXs (e.g., LOC_Os08g41090) were more induced in LT than CO after HT treatment. Differential induction of these antioxidant encoding genes indicates a substantial effect of the genetic background on antioxidant activity, and this is consistent with the aforementioned differential POX enzyme activities between CO and LT at 48 hpi.

In class II, genes involved in the synthesis and signaling pathway of SA, jasmonic acid (JA), ethylene (ET), abscisic acid (ABA) and other hormonal pathways were considered. We detected a significant up-regulation of genes encoding for SAM dependent carboxyl methyltransferases in response to both HT and Mo, including LOC_Os06g13310 and OsBISAMT1 (LOC_Os11g15040), the enzyme that catalyzes the conversion of SA to MeSA. LOC_Os06g13310 and OsBISAMT1 were more induced in plants pre-exposed to $35^{\circ} \mathrm{C}$ than $28^{\circ} \mathrm{C}$ in both NILs (additional file S2). We also looked at the differential expression of PAL genes (e.g., OsPAL5; LOC_Os02g41670, OsPAL1; LOC_Os02g41680, ZB8; LOC_Os05g35290, OsPAL2; LOC_Os04g43760 and OsPAL7; LOC_Os04g43800) and NPRI genes (e.g., LOC_Os01g09800) in Mo inoculated plants.We detected reduced expression of these genes in response to Mo and HT in both NILs. 
The JA pathway genes, e.g., 12-oxophytodienoate reductase 9 (OPR9; LOC_Os01g27240), were more induced in $\mathrm{CO}+35^{\circ} \mathrm{C}+\mathrm{Mo}$ and $\mathrm{LT}+35^{\circ} \mathrm{C}+\mathrm{Mo}$ than $\mathrm{CO}+28^{\circ} \mathrm{C}+\mathrm{Mo}$. Genes encoding for jasmonate O-methyltransferases (e.g., LOC_Os12g13800 and LOC_Os09g17560) and jasmonate induced jacalin-like lectins (e.g., LOC_Os11g32210) were also more induced in $\mathrm{CO}+35^{\circ} \mathrm{C}+\mathrm{Mo}$ than $\mathrm{CO}+28^{\circ} \mathrm{C}+\mathrm{Mo}$. Interestingly, similar genes (e.g., LOC_Os06g2182, LOC_Os12g14440 and an orthologue of maize O-methyltransferase ZRP4; LOC_Os $10 \mathrm{~g} 02880$ ) were more induced in LT than CO in response to Mo at $28^{\circ} \mathrm{C}$.

For ET pathway, oxidoreductases from 2OG-Fe(II) oxygenase family (e.g., LOC_Os06g07914), ethylene responsive transcriptional coactivator named multiprotein bridging factor 1c (MBF1c; LOC_Os06g39240), dehydration-responsive element-binding protein $1 \mathrm{G}$ (DREB1G; LOC_Os02g45450), ethylene-responsive transcription factor 5 (ERF5; LOC_Os10g41330), 1-aminocyclopropane-1-carboxylate deaminase (LOC_Os02g53330) and basic helix-loop-helix transcription factors (TFs; e.g., bhlh65, bhlh108 and bhlh56) were more induced in plants pre-exposed to $35^{\circ} \mathrm{C}$ than $28^{\circ} \mathrm{C}$ in both NILs.

Among the genes involved in other hormonal pathways, auxin response genes (e.g., OsIAA13; LOC_Os03g53150, OsGH3.2; LOC_Os01g55940, OsGH3.5; LOC_Os05g50890, OsSOUR1; LOC_Os01g06230 and $A R F 19$ ) were significantly induced in $\mathrm{CO}+35^{\circ} \mathrm{C}+\mathrm{Mo}$ than $\mathrm{CO}+28^{\circ} \mathrm{C}+\mathrm{Mo}$. In $\mathrm{ABA}$ pathway, GEM (LOC_Os02g42430) was more induced in $\mathrm{CO}+35^{\circ} \mathrm{C}+\mathrm{Mo}$ and $\mathrm{LT}+35^{\circ} \mathrm{C}+\mathrm{Mo}$ than $\mathrm{CO}+28^{\circ} \mathrm{C}+\mathrm{Mo}$. In contrast, HVA22 (LOC_Os11g05800), OsBBD1 (LOC_Os01g50622), ABA3 (LOC_Os09g38772) were more induced in LT than $\mathrm{CO}$ in response to $\mathrm{HT}+\mathrm{Mo}$.

In class III, we considered significantly regulated genes encoding for nucleotide-binding and leucine-rich repeat (NB-LRR) proteins and receptor like kinases (RLKs). In our dataset, 61 and 75 genes encoding for R like proteins were up-regulated (>4-fold) in $\mathrm{LT}+28^{\circ} \mathrm{C}+\mathrm{Mo}$ and $\mathrm{CO}+28^{\circ} \mathrm{C}+\mathrm{Mo}$, respectively (additional file S2). This number however decreased to 50 and 63 in $\mathrm{LT}+35^{\circ} \mathrm{C}+\mathrm{Mo}$ and $\mathrm{CO}+35^{\circ} \mathrm{C}+\mathrm{Mo}$, respectively, and their expression was significantly lower at $35^{\circ} \mathrm{C}$. Transcript levels of Pi54 (LOC_Os11g42010) were significantly lower at $35^{\circ} \mathrm{C}$ than $28^{\circ} \mathrm{C}$ (Fig. 8). Exceptions were observed in LT, in which Pit (LOC_Os01g05620) was evidently more induced at $35^{\circ} \mathrm{C}$ compared to $28^{\circ} \mathrm{C}$. Further, NBS-LRR disease resistance protein (LOC_Os01g05600) which shares 91.9\% sequence homology to Pit, an orthologue of RPMI (LOC_Os11g11770), Yr10 (LOC_Os12g17090) and a GTPase of unknown function (LOC_Os08g10649) were highly induced in LT but not in CO. Alternatively, orthologues of Avena sativa NBS-LRR type disease resistance protein O2 (LOC_Os04g43440), RPM1 (LOC_Os06g48520), RGA3 (LOC_Os11g10770) and Xal (LOC_Os04g53120) were more induced in $\mathrm{CO}+35^{\circ} \mathrm{C}+\mathrm{Mo}$ than $\mathrm{CO}+28^{\circ} \mathrm{C}+\mathrm{Mo}$. The high induction of these genes in $\mathrm{CO}+35^{\circ} \mathrm{C}+\mathrm{Mo}$ compared to $\mathrm{CO}+28^{\circ} \mathrm{C}+\mathrm{Mo}$ may suggest a potential role in rice resistance against Mo.

Receptor like kinases (RLKs) are among the largest class of proteins, with about 1100 reported in rice, so far (Kawano and Shimamoto 2013). Our transcriptome analysis revealed a large number of RLK genes expressed in 
response to Mo than HT (Additional file S2), and their expression was significantly lower at $35^{\circ} \mathrm{C}$. Exceptions included transcription of genes encoding for SHR5 receptors, some of them were relatively less affected by alterations in temperature. For instance, transcript levels of SHR5 (LOC_Os05g17810) were significantly higher in $\mathrm{CO}+35^{\circ} \mathrm{C}+\mathrm{Mo}$ than $\mathrm{CO}+28^{\circ} \mathrm{C}+\mathrm{Mo}$. The same was true for a leucine-rich repeat receptor-like protein kinase 1 (LOC_Os10g02990) and S-domain receptor-like protein kinase (LOC_Os11g10290). In LT, senescence induced RLKs (e.g., LOC_Os09g19380 and LOC_Os05g17604), glutamate receptor (LOC_Os06g08900), OsWAK36 and OsWAK43 were more induced in HT treated plants than plants grown and inoculated at $28^{\circ} \mathrm{C}$.

In class IV, several TFs were more induced in response to Mo than HT (additional file S2). MYB family genes were the most regulated at HT. This was consistent with a high frequency (>90\%) of cis-elements for water stress (MYBCORE) and dehydration stress (MYB1AT) response in both sense and antisense strands of most temperature stress responsive DEG. MYBAS1 (LOC_Os11g47460) and R1-MYB/MYB-like subfamily genes (e.g., LOC_Os01g60850, LOC_Os03g55840 and LOC_Os01g74600) were highly induced at HT in both NILs. Among WRKY genes, OsWRKY111 (LOC_Os05g50700) was strongly induced in both NILs, whereas OsWRKY84 and OsWRKY65 (LOC_Os12g02470) were more induced in $\mathrm{CO}+35^{\circ} \mathrm{C}+\mathrm{Mo}$ than $\mathrm{CO}+28^{\circ} \mathrm{C}+\mathrm{Mo}$. HT treated plants also showed increased transcript levels of splicing factor U2af small subunit A (LOC_Os09g31482) involved in mRNA processing, and a B-Box Zinc Finger Gene (OsBBX22) in both NILs.

Alternatively, bHLH genes, (bHLH-68; LOC_Os04g23550, bHLH-114; LOC_Os08g38210 and LOC_Os02g45170) were significantly induced in CO than LT at HT. Genes encoding for ONAC12 (LOC_Os05g37080), ONAC43 (LOC_Os02g06950), a zinc binding protein (LOC_Os06g45540) and ROC6 (LOC_Os09g35760) were more induced in $\mathrm{CO}+35^{\circ} \mathrm{C}+\mathrm{Mo}$ than $\mathrm{CO}+28^{\circ} \mathrm{C}+\mathrm{Mo}$. In contrast, transcript levels of SWIB/MDM2 complex (LOC_Os03g55310) involved in chromatin remodeling, bZIP genes (e.g., bZIP62; LOC_Os07g48660 and LOC_Os05g16640), OsMADS25 (LOC_Os04g23910), WRKY4 (LOC_Os03g55164), $b H L H-58, b H L H-114$ and $b H L H-63$ were generally more induced in LT than CO.

In class V, LT showed increased expression of most photosynthesis related genes compared to CO. Genes encoding for oxygen evolving enhancer protein 3 (OEE3; LOC_Os02g36850) required for photosystem II assembly/stability, chloroplastic group IIA intron splicing facilitator (CRS1; LOC_Os07g30670) involved in chloroplast protein translation and $2 \mathrm{Fe}-2 \mathrm{~S}$ iron-sulfur cluster binding protein (LOC_Os07g30670) were generally >10-fold induced in response to HT. In addition, plastid transcriptionally active12 (PTAC12; LOC_Os01g56350), phosphoenolpyruvate phosphate translocator2 (PPT2; LOC_Os08g25624), a metal iron binding protein (MT3B; LOC_Os05g11320), cytochrome P450 (LOC_Os03g55230) and proliferating cell nuclear antigen (PCNA; LOC_Os02g56130) were more induced in response to HT than Mo. A putative photosystem Q (LOC_Os10g21192) and a photosynthetic reaction center protein (LOC_Os10g39880) were however specifically induced in CO but not in LT. Several cytochrome P450s, including LOC_Os01g36294 and LOC_Os10g30390, 
and photosystem II $10 \mathrm{kDa}$ polypeptide encoding genes (e.g., LOC_Os07g05360 and LOC_Os07g05365) were induced >30-fold in both NILs. These genes likely play a significant role in protecting rice PSII from perturbations resulting from heat stress and pathogen infection.

Several genes involved in lipid metabolism were background specific. For instance, the GDSL like gene (LOC_Os01g11730) was stronger induced in LT than $\mathrm{CO}$ at $35^{\circ} \mathrm{C}$. However, amino acid metabolism genes encoding for asparagine synthetase, alanine-glyoxylate aminotransferase, isovaleryl-CoA dehydrogenase and 2aminoethanethiol dioxygenase were $>40$-fold induced in both NILs in response to Mo. Genes encoding for fumarylacetoacetase, 2-isopropylmalate synthase B and D-3-phosphoglycerate dehydrogenase were specifically induced in response to HT.

In contrast, genes involved in the TCA cycle, carbon and amino acid metabolism were largely suppressed by HT treatment. Nonetheless, several genes encoding for S-adenosyl-L-methionine, and one gene encoding for starch mobilization (Amy3B; LOC_Os09g28420) were induced >8-fold in both NILs in response to HT. In addition, genes encoding for fumarylacetoacetase (LOC_Os02g10310), 2-isopropylmalate synthase B (LOC_Os12g04440) and D-3-phosphoglycerate dehydrogenase (LOC_Os04g55720) were more induced in response to HT than Mo. Some genes encoding for enzymes involved in the transfer of glucose from UDPglucose to lipids were background specific. For instance, genes encoding for UDP-glucoronosyl (LOC_Os09g34250) and UDP-glucosyl transferase (LOC_Os02g10880) were

\subsection{Expression of PRs and secondary metabolism genes}

Pathogenesis related (PR) proteins are induced by pathogenic infection through the coordinated action of SA, JA and ET signaling pathways. We found a significant overlap in transcript accumulation of several PR encoding genes between HT and Mo treated plants (Fig. 9). At HT, we detected a significant induction of several PR6 genes in both backgrounds. Some PR genes were background specific. For instance, PR3 (e.g., CHIT17; LOC_Os05g33130) and PR2 (Gns6; LOC_Os01g71350) were significantly induced in $\mathrm{CO}+35^{\circ} \mathrm{C}$ but not in $\mathrm{LT}+35^{\circ} \mathrm{C}$, whereas PR-5 (TLP-D34; LOC_Os12g43380) was $>10$-fold induced in $\mathrm{LT}+35^{\circ} \mathrm{C}$ but not in CO$+35^{\circ} \mathrm{C}$. Transcript accumulation of the gemine like protein (GLP) encoding genes also overlapped between the two backgrounds. For instance, GLP1 (LOC_Os04g22080) was $>100$-fold expressed in LT $+35^{\circ} \mathrm{C}+\mathrm{Mo}$, but was not

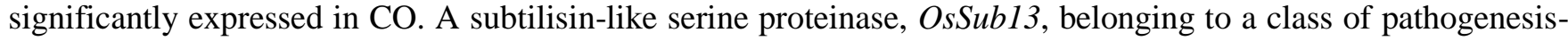
related proteins (Jorda and Vera 2000), and a protein-disulfide isomerase (OsPDIL1-1), involved in the biosynthesis of a group of plant defence peptides called cyclotides (Jennings et al., 2001), were more induced in LT than in $\mathrm{CO}$ in response to Mo. 
Secondary metabolism, including the production of phytoalexins, plays a significant role in plant defence against pathogens. Activated secondary metabolism sub-pathways included the phenylpropanoid, flavonoid and terpenoid metabolites (Additional file S2). The expression of genes encoding for the biosynthetic enzymes of diterpenoid phytoalexins was either low or down-regulated in plants exposed to HT. Nonetheless, terpene synthase (LOC_Os04g27430) was induced $>30$-fold in $\mathrm{CO}+35^{\circ} \mathrm{C}$ and $\mathrm{LT}+35^{\circ} \mathrm{C}$. On the other hand, Mo infection increased transcript levels of phytocasanes biosynthetic gene (OsKSL7; LOC_Os02g36140) in both NILs. Furthermore, we detected the induction of a NADPH-dependent codeinone reductase (LOC_Os10g02490) after HT treatment in both NILs. We speculate that codeinone reductase, together with the aforementioned 12oxophytodienoate reductase and OMTs may play major roles in the production of secondary metabolites.

2.7 Validation of differential gene expression of known temperature and infection responsive rice genes by qRT$P C R$

The expression profiles of known responsive rice genes were validated by analyzing their up-regulation at $35^{\circ} \mathrm{C}$ and during $35^{\circ} \mathrm{C}+\mathrm{Mo}$ interaction (Fig. S4A-I). The response of all the measured genes was similar but the magnitude of responses was greater in RNA-Seq than in qPCR. This analysis confirmed the high induction of nine genes, including $O S F K B P 65$, in plants exposed to $35^{\circ} \mathrm{C}$ compared to $28^{\circ} \mathrm{C}$, prior to Mo inoculation.

\section{Discussion}

In this study, we tested the hypothesis that elevated temperature would weaken rice defence against Mo, irrespective of the genetic backgrounds in which the $\mathrm{R}$ gene (Pi54) is introgressed. We used two rice genetic backgrounds with (CO and LT) and without (Co39 and LTH) Pi54. After exposure to $28^{\circ} \mathrm{C}$ and $35^{\circ} \mathrm{C}$ for $7 \mathrm{~d}$, the two backgrounds showed contrasting responses to Mo infection. At $28^{\circ} \mathrm{C}, \mathrm{CO}, \mathrm{Co} 39$ and $\mathrm{LTH}$ displayed a more severe disease phenotype than LT. CO and LT were used for biochemical and transcriptome analysis to determine the cause of contrasting reactions to Mo despite carrying the same R gene. At $28^{\circ} \mathrm{C}$, LT plants showed more intense callose deposits and cell wall fluorescence than $\mathrm{CO}$, suggesting that the genetic background of LT facilitated the function of Pi54 more than the background of CO. Interestingly, upon pre-inoculative exposure to $35^{\circ} \mathrm{C}$, resistance responses were enhanced in both NILs. Moreover, callose deposits and cell wall fluorescence of the attacked epidermal cells were more intense at $35^{\circ} \mathrm{C}$ than $28^{\circ} \mathrm{C}$.

Intriguingly, these HT induced rice defence responses were contrasted by a decrease in Pi54 expression at HT. The reduced expression of Pi54, in spite of enhanced resistance at HT, suggested that HT probably enhanced plant resistance by either increasing the baseline levels of endogenous Pi54 downstream products thereby decreasing its expression or acted independent of Pi54. 
In view of these findings, it was critical to further define through biochemical and transcriptome analysis the factors that reinforce plant defences against pathogens at HT. We will jointly discuss the gene expression data and the defence related biochemical changes to ascertain their functional connection in this study.

Our data showed a substantially higher number of DEG in Mo infected plants than HT treated plants, suggesting that the rice-Mo interaction underlies a more intense genome transcriptional regulation than HT stress. Exposure to $35^{\circ} \mathrm{C}+$ Mo was also significantly different from HT (single stress) induced transcriptional changes, and genes expressed in $35^{\circ} \mathrm{C}+\mathrm{Mo}$ clustered closely with $28^{\circ} \mathrm{C}+\mathrm{Mo}$, indicating that transcriptional changes due to HT were overidden by Mo infection. Thus, plants probably tend to shift their response to pathogens when HT and pathogen stresses occur simulteneously. A strong and simultaneous induction of some heat and pathogen stress response genes in combined stress $\left(35^{\circ} \mathrm{C}+\mathrm{Mo}\right)$, however, suggested a considerable additive role of temperature in invoking plant defence response. Several of these genes were enriched in oxidation-reduction processes (GO:0055114), suggesting that oxidation-reduction reactions were the likely upstream signals in rice defence response to both HT and Mo. However, oxidation-reduction was similarly enriched in a susceptible reaction $(\mathrm{CO}$ plants infected with Mo at $28^{\circ} \mathrm{C}$ ). This suggests that other mechanisms appeared to be necessary for successful restriction of pathogenesis at $35^{\circ} \mathrm{C}$. These include, but probably not limited to, the induction of callose deposition. Luna et al. (2010) previously reported that callose deposition is preceded by PAMP triggered $\mathrm{H}_{2} \mathrm{O}_{2}$. Our biochemical analysis showed significantly higher $\mathrm{H}_{2} \mathrm{O}_{2}$ levels in both NILs after HT treatment, suggesting that an earlier activation of a defence response associated with callose accumulation was prompted by HT associated induction of ROS prior to Mo infection. The higher induction of cell membrane NADPH oxidases (OsNox9 and RbohD) in plants pre-exposed to HT followed by Mo inoculation is consistent with increased callose accumulation. However, the role of HT in inducing plant defence against pathogens has been challenged previously. HT was reported to cause downregulation of superoxide, NADPH oxidases and hypersensitive response (HR) in Nicotiana tabacum and compromised $\mathrm{N}$ gene mediated resistance to Tobacco mosaic virus (Király et al., 2008). Contrary to these findings, it is possible that HT reprograms signal transduction components, including stress-generated ROS, to induce or compromise disease resistance depending on the host plant and probably the duration of HT stress. The plasticity of $\mathrm{CO}$ in this study attests to this, and suggests that this plasticity could be employed by some crops for adaptation to both HT and pathogen infection in a changing climate. This may also include adaptability to ROS accumulation and signal transductions that modulate redox balances by activating either peroxidases (POX), plasma membrane calcium ion channels or both.

More than 20 POX genes were differentially expressed in this study. However, POX activity was not significantly different between $\mathrm{CO}$ plants exposed to $28^{\circ} \mathrm{C}$ and $35^{\circ} \mathrm{C}$ followed by Mo inoculation at 24 hpi. Moreover, POX activity was significantly lower in LT than CO plants infected with Mo at 48 hpi. This inconsistency, despite higher POX activity in $\mathrm{CO}$ at $35^{\circ} \mathrm{C}$ than $28^{\circ} \mathrm{C}$, showed ambiguity in $\mathrm{POX}$ involvement in 
rice defence against Mo, and would require further experimental proof. On the other hand, calcium metabolism is associated with ROS signaling, and ROS are apparently required to prime $\mathrm{Ca}^{2+}$ influx after elicitation (Torres et al., 2006). Calcium entering the cytoplasm is also implicated in activating the plasma membrane localized and $\mathrm{Ca}^{2+}$ dependent 1,3-B-glucan synthase, thereby effecting callose deposition in a localized manner (Kauss 1990). We detected several up regulated genes involved in calcium signaling in response to HT and Mo infection; and cellular response to calcium ion (GO:0071277) was enriched consistently with hydrogen peroxide biosynthetic process (GO:0050665). It appears therefore that $\mathrm{Ca}^{2+}$ is involved in callose synthesis, and the interplay between ROS, $\mathrm{Ca}^{2+}$ and callose likely determines the dynamics associated with pre-penetrative defence at HT.

There are also several reports on abiotic and biotic stress induction of ROS and their interaction with phytohormones and associated signaling pathways involved in local and systemic plant defence (reviewed by Ben Rejeb et al., 2014). With respect to systemic defence, conventional responses include production of SA, JA, ET and ABA, and subsequently, their derivatives, e.g., MeSA and MeJA and catalytic enzymes. We therefore also focused on these phytohormones and their corresponding genes. Salicylic acid is the most reported phytohormone in plant defence; however, there are conflicting reports on its role against pathogens, with some reports suggesting that SA appears to be simply an effective therapeutic agent (Rivas-San and Plasencia, 2011). Our data showed decreased levels of SA in LT compared to $\mathrm{CO}$ at $28^{\circ} \mathrm{C}$, despite increased levels in both NILs at HT (single stress). Considering that $\mathrm{CO}$ had a more severe disease phenotype compared to LT, it is possible that the increased level of SA in $\mathrm{CO}$ at $28^{\circ} \mathrm{C}$ did not induce effective defence response against Mo. This finding raises the possibility that SA may not directly confer rice blast resistance.

Earlier reports have shown that JA-induced AtBSMT1 probably depletes the SA pool in plants by antagonizing the SA synthesis pathway (Chen et al., 2003). It is tempting to suggest that the strong induction of OsBISAMT1, which catalyzes the conversion of SA to MeSA, at HT is consistent with this. In addition, it has been suggested that HT may promote JA synthesis and signaling to repress SA signaling leading to a suppression of SA-mediated defence responses (Wang et al., 2009). Studies have also shown that exogenous SA promotes the JA-dependent induction of the defensin gene PDF1.2, when applied at low concentrations (Kazan and Manners 2008). Considering that MeSA is a critical mobile signal in plant tissues and occurs at low concentrations compared to SA (Park et al., 2007), our results suggest that MeSA instead of SA modulates JA in activating genes encoding for defensins (e.g., DEFL9; LOC_Os06g22919 and DEFL49; LOC_Os04g31250) at 35 ${ }^{\circ}$. A key question is whether the interaction between MeSA and JA is sufficient to induced effective resistance or other phytohormones are involved? Mechanistic details on such interaction are still lacking. However, it should be noted that ABA is involved in signaling processes inducing JA-dependent defence responses in systemic tissues through its activity on MYCs (Nguyen et al., 2016). MYCs induce plant resistance by regulating many genes encoding JA metabolic enzymes such as LOX, allene oxide synthase (AOS), allene oxide cyclase (AOC) and 12-oxophytodienoate 
reductase (OPR) (Takagi et al., 2016). A strong induction of $O s B B D 1$, involved in ABA derived callose deposition, and 12-oxophytodienoate reductase, which catalyzes the last step in the biosynthesis of JA, in this study, suggests that ABA and JA signalling are key regulatory steps in HT induced resistance pathway. JA and its methyl ester, methyl jasmonate (MeJA), probably complement each other in tailoring downstream defence pathways, considering that Jasmonate-O-methyltransferase (JMT), which converts JA to MeJA and other lipid derivatives, was strongly up-regulated in plants exposed to $35^{\circ} \mathrm{C}+$ Mo. Endogenous $\mathrm{JA} / \mathrm{MeJA}$ has also been reported to regulate phytoalexin biosynthesis in rice (Shimizu et al., 2012). Plants pre-exposed to $35^{\circ} \mathrm{C}$ followed by Mo infection, exhibited increased expression of JA regulated genes, including flavonoid-7-OMT (LOC_Os09g17560) and LOC_Os12g13800, that have been implicated in sakuranetin biosynthesis (Shimizu et al., 2012; Park et al., 2013). This suggests that sakuranetin is one of the crucial components contributing to rice resistance against Mo at HT.

Additional signals from HT exposure could be explained by other mechanisms such as ethylene signaling pathways. Ethylene is synthesized from methionine and has been shown to increase in methionine treated rice leaves (Nakazato et al., 2000). The induction of a putative methionine-S-oxide reductase (LOC_Os03g04370, >8fold), which reverses the oxidation of methionine to methionine sulfoxide (MetSO), and several SAM dependent carboxyl methyl transferases, in this study, suggests that methionine is synthesize in response to HT for multiple purposes. Consistent with this, Module 13 is associated with cell cycle and S-adenosylmethionamine biosynthetic process. It is possible that increased synthesis of methionine and its derivatives contributes to host resistance. Thus, in addition to $\mathrm{ABA}, \mathrm{H}_{2} \mathrm{O}_{2}, \mathrm{JA}$, callose deposition, defensins and sakuranetin biosynthesis, we speculate that the integrated signals from methionine and its derivatives are crucial for inducing seedling resistance to Mo.

Correlating with this was the increased transcript levels of $M B F 1 c$ in $\mathrm{CO}$ plants exposed to $35^{\circ} \mathrm{C}$ compared to $28^{\circ} \mathrm{C}$. $M B F 1 \mathrm{c}$ is a transcriptional co-activator required for basal thermotolerance and functions upstream to ethylene during heat stress (Suzuki et al., 2011). Constitutive expression of MBF1c in transgenic Arabidopsis plants increases resistance against bacterial infections, heat and osmotic stress by partially activating the ethyleneresponse signal transduction pathway, but without significant increases in SA levels (Suzuki et al., 2008). Considering that ethylene burst is one of the earliest events in HR (Seo et al., 2011), the up-regulation of MBF1c in plants exposed to $35^{\circ} \mathrm{C}$ probably fine-tunes ET signaling pathway. An increased transcript level of ERF5, an orthologue of Arabidopsis ERF96, is consistent with this, and suggests that ET is involved in HT induced plant resistance. However, ET-mediated responses are also synergistically regulated by gibberellins (GAs), brasinostreroids (BRs) and Auxins (AUXs). Increased expression of genes in the AUX, GA and BR signaling pathways and antagonistic regulators such as OsIAA13, OsGH3.2, OsGH3.5, ARF19 and ERF5 was detected in this study, suggesting that internal dynamics are involved in fine-tuning the defence responses associated with these multiple hormones. 
Downstream of these hormonal dynamics are various kinds of defence related transcription factors, including U2 small nuclear ribonucleoprotein auxiliary factor $(U 2 A F)$, WRKYs, zinc finger RING type, OsEREBPs, MYBs, HB, bHLH, zinc finger (ZF) family and basic region/Leu zipper motif (bZIP) family. $U 2 A F$ plays a crucial role in the recognition of a 3 '-splice site which contributes to the fine-tuned control of pre-mRNA splicing. $U 2 A F$ was expressed in all treatments and could be an important candidate to explore the crosstalk between HT and pathogen response. One of the OsWRKY IIa encoding genes, OsWRKY84, was also strongly induced in $\mathrm{CO}+35^{\circ} \mathrm{C}+\mathrm{Mo}$ than $\mathrm{CO}+28^{\circ} \mathrm{C}+\mathrm{Mo}$. OsWRKY84 was previously reported to be over-expressed in response to xylanases in suspension-cultured rice cells. Mo is known to induce endoxylanases for horizontal expansion in infected leaves (Nguyen et al., 2011). Since the functional role of OsWRKY84 is not well understood, it could be a potential target for further investigation.

Downstream of these TFs are other HT and Mo response genes. Perhaps the most compelling observation was the significant higher expression of Peptidyl-prolyl isomerases $(O s F K B P 65)$ in $\mathrm{CO}+35^{\circ} \mathrm{C}+\mathrm{Mo}$ and $\mathrm{LT}+35^{\circ} \mathrm{C}+$ Mo. OsFKBP 65 positively modulates heat tolerance by interacting with AtHSP90.1, and increases AtHsfA2-mediated accumulation of small HSPs (Meiri and Breiman, 2009). Interestingly, HSP90 is a hub gene of module 7. This module was highly correlated with Mo infection. The GO analysis indicated that the genes in module 7 are involved in signal transduction and defence response to bacterium. Thus, HSP90 probably contribute to resistance at HT through its interaction with OsFKBP65. Previous studies also implicate FKBPs in disease resistance. A peptidyl-prolyl, named microbial factor 3 (MF3), was previously shown to induce resistance to A. longipes and TMV in tobacco, and Bipolaris sorokiniana in wheat (Shumilina et al., 2006). A recent study by Narsai et al., 2013, also showed over representation of peptidyl isomerases in rice against bacterial and parasitic infection. Thus, we speculate that $O S F K B P 65$ is involved in multiple roles that may need to be examined further.

Other genes identified in response to HT included LOC_Os03g62720, an exosome complex exonuclease involved in the degradation of unstable mRNAs containing AU-rich elements (AREs) within their 3'-untranslated regions. This gene is a hub gene of module 1, and this module positively correlates with HT treatment. Genes in module 1 are significantly enriched in translation regulator activity (GO:0045182), suggesting that LOC_Os03g62720 may play a key role in regulating protein synthesis at HT.

Overall, the present study provided a broad insight into potential defence responses of rice to HT and Mo. We have shown that rice lines carrying Pi54 respond to Mo by rapid induction of callose and $\mathrm{H}_{2} \mathrm{O}_{2}$, and these resistance responses are stronger at $35^{\circ} \mathrm{C}$ than $28^{\circ} \mathrm{C}$. Previously we demonstrated that a rice cultivar Nipponbare is susceptible to M. oryzae at HT (Onaga et al., 2017). Importantly, in the same study, pathogen putative effector transcript abundance correlated with susceptibility at HT. Contrary to the hypothesis that in planta pathogen effector transcript abundance increases host susceptibility at HT, our results demonstrate that plant plasticity is 
one of the main strategies for adaptation to both HT and pathogen infection in a changing climate. For instance, we have shown that despite the impact of HT on Pi54 transcription, the accumulation of modest Pi54 transcripts or downstream products reliably detect the pathogen when augmented with pre-exposure to HT. Among the defence networks probably associated with HT are the defence dynamics associated with phytohormone interactions. Crosstalk between MeSA, ABA, MeJA/JA and ET and their signaling pathways appears to be a key defence mechanism of rice against Mo. We hypothize that ABA accumulates at HT and its signaling pathway is required to increase callose accumulation in infected plants. The defence response associated with MeJA/JA and ET is secondary and ABA possibly fine tunes their synthesis and signaling. Figure 10 shows a hypothetical example of a reaction pathway leading to a defence response in rice against Mo. Due to the strong mutual antagonism between phytohormones, e.g., ET and ABA, our findings do not necessarily rule out the possibility that some defence pathways may be affected negatively, although this may depend on the host plant. Additional focused analyses on these hormones will be required in the future to further evaluate our multi-hormone interaction hypothesis.

\section{Material and methods}

\subsection{Plant and fungal material and rice blast inoculation}

Two genotypes, Li-Jiang-Xin-Tuan-He-Gu (LTH, Oryza japonica) and Co39 (Oryza indica) with and without Pi54, were used as hosts in this experiment. LTH is widely identified as a genetic background for the development of NILs, whereas Co39, a short duration O. indica cultivar from India with high susceptibility to tropical blast isolates, was recently introduced as a second background for the development of NILs. The experiment included three biological replicates per treatment. Seeds of LTH and Co39 (lacking or having Pi54) were soaked in water, incubated and pre-germinated on filter papers in Petri dishes in the dark at $32^{\circ} \mathrm{C}$ until the seeds sprouted at about 72 hours. Seedlings were transferred to soil filled pots at a rate of 3 seedlings per pot. The plants were grown in the greenhouse at $27 \pm 2^{\circ} \mathrm{C}$ with a photoperiod of $14 \mathrm{~h}$ for $21 \mathrm{~d}$ and then transferred to growth chambers at $28^{\circ} \mathrm{C}$ and $35^{\circ} \mathrm{C}$ for 7 days. After HT exposure, all plants were kept at $28^{\circ} \mathrm{C}$ for inoculation to allow fungal infection at equal conditions. Inoculation was performed using $M$. oryzae isolate, TAN211.16, from Tanzania. This strain was selected for rice-Mo interaction at high temperature study because it was aggressive on most of the isogenic lines tested in our greenhouse, including Pi54 in Co39 background. TAN211.16 was grown in petri dishes containing V8 agar under $14 \mathrm{~h}$ of fluorescent light at $25^{\circ} \mathrm{C}$ for 12 days. Three days prior to inoculation, cultures were exposed to low levels of visible and near-UV radiation to maximize sporulation. Inoculation was performed by spraying a conidial suspension containing $0.05 \%$ Tween 20 onto rice seedlings. The inoculated plants were incubated for $24 \mathrm{~h}$ at $28^{\circ} \mathrm{C}$ and $90 \%$ relative humidity in the dark and then transferred 
493

494

495

496

497

498

499

500

501

502

503

504

505

506

507

508

509

510

511

512

513

514

515

516

517

518

519

520

521

522

523

524

525

back to $12 \mathrm{~h}$ of light for additional $24 \mathrm{~h}$ before leaf sampling. Some plants were maintained at $35^{\circ} \mathrm{C}$ and $28^{\circ} \mathrm{C}$ for 10 days after inoculation for disease assessment. Disease assessment was repeated two times to confirm the presence of lesions. Disease reaction ratings and disease progress calculations were conducted as previously described by Onaga et al. (2015).

\subsection{Histochemistry and microscopy}

Callose staining was carried out according to the method of Hao et al. (2008). Observations were made with a light microscopy (Leica, Bensheim, Germany) equipped with a Leica DC300F camera. The yellow spots that corresponded to the stained callose were analyzed for number of pixels with the GNU Image Manipulation program (GIMP, http://www.gimp.org/). Callose intensity was expressed as the percentage of yellow pixels per total pixels on the digital photographs of the infected areas.

\subsection{Measurement of hydrogen peroxide $\left(\mathrm{H}_{2} \mathrm{O}_{2}\right)$}

Leaf samples were collected 24 and 48 hpi and immediately ground in liquid nitrogen. The ground powder was extracted in $5 \% \mathrm{w} / \mathrm{v}$ metaphosphoric acid. The samples were centrifuged at $5000 \times g$ for $60 \mathrm{~min}$. The supernatant was adjusted to $\mathrm{pH} 6.5 \mathrm{using} 1 \mathrm{M}$ tricine in $6 \mathrm{M} \mathrm{NaOH}$, and the initial amount of NADH was measured at $340 \mathrm{~nm}$ $\left(\mathrm{OD}_{1}\right)$ using SPECORD 40 (Analytik, Jena, Germany). Horseradish peroxidase (350 $\mu \mathrm{l}^{-1} ; 2500 \mathrm{U} \mathrm{ml}^{-1}$ ) dissolved in $25 \mathrm{mM}$ sodium phosphate buffer ( $\mathrm{pH} 7.0)$ was added and the mixture was incubated at room temperature. The absorbance changes at $340 \mathrm{~nm}$ were measured at $25^{\circ} \mathrm{C}, 60 \mathrm{~min}$ after the addition of horseradish peroxidase $\left(\mathrm{OD}_{2}\right)$. The $\mathrm{H}_{2} \mathrm{O}_{2}$ contents were determined by a calibration curve using known amounts of $\mathrm{H}_{2} \mathrm{O}_{2}$ and expressed as micromoles per gram of fresh weight (FW).

\subsection{Guaiacol peroxidase activity}

Fresh leaf samples weighing $300 \mathrm{mg}$ were homogenized in $3 \mathrm{ml}$ of cold 100mM Na-phosphate buffer (pH 7.0). The homogenates were centrifuged at 5,000 x $\mathrm{g}$ for $30 \mathrm{~min}$, and the dialyzed enzyme extract was used for the

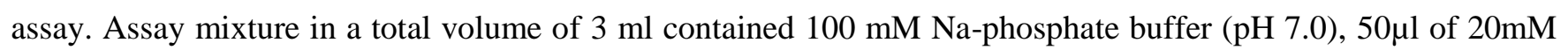
guaiacol solution, $30 \mu \mathrm{l}$ of $12.3 \mathrm{mM}$ hydrogen peroxide and $50 \mu \mathrm{l}$ of enzyme extract. Increase in absorbance was measured at $420 \mathrm{~nm}$ (extinction coefficient of $26.6 \mathrm{mM} \_1 \mathrm{~cm} \_1$ ) at $30 \mathrm{~s}$ intervals up to $3 \mathrm{~min}$, using SPECORD 40, Analytikjena AG (Germany). Enzyme specific activity was expressed as mKatal. 


\subsection{Salicylic acid (SA) determination}

Accumulation of SA was examined using a Merck-Hitachi high performance liquid chromatography (HPLC; Merck KGaA) as described previously (Kamble and Bhargava, 2007).

\subsection{Real-time RT-PCR analysis}

Total RNA was isolated using Trizol reagent (Invitrogen, Carlsbad, CA) according to the manufacturer's instructions. Gene-specific primers were designed using the software Primer3Plus (http://www.bioinformatics.nl/cgi-bin/primer3plus/primer3plus.cgi/). Primer sequences are listed in (Additional file S2). Relative gene expression was determined by quantitative real time PCR (RT-PCR) on a Bio-Rad CFX384 real time system using SYBR Green dye (Bio-Rad, California, USA). Reaction was performed in a 10 $\mu \mathrm{L}$ reaction mixture that consisted of $5 \mu \mathrm{L}$ of 2 X SYBR Green PCR Master Mix, $400 \mathrm{nM}$ of both forward and reverse primers and 20ng of cDNA. Thermal cycling was started at $95^{\circ} \mathrm{C}$ for $15 \mathrm{~min}$, followed by 35 cycles of $95^{\circ} \mathrm{C}$ for $20 \mathrm{~s}, 62{ }^{\circ} \mathrm{C}$ for $30 \mathrm{~s}$ and $72^{\circ} \mathrm{C}$ for $20 \mathrm{~s}$. The final elongation was performed for 5 min at $72^{\circ} \mathrm{C}$. The melting curve was obtained by heating the reaction temperature to $95^{\circ} \mathrm{C}$ for $1 \mathrm{~min}$, cooling to $55^{\circ} \mathrm{C}$ for the next minute, then slowly increasing the temperature from $65^{\circ} \mathrm{C}$ to $95^{\circ} \mathrm{C}$ in a rate of $0.5^{\circ} \mathrm{C} \mathrm{s}^{-1}$. The primer efficiency was determined using a standard curve. Standard curves with a correlation $\geq 0.98$ and efficiency between $90 \%$ and $110 \%$ were considered as appropriate for calibration, and the efficiency was used for the calculation of relative gene expression. The data were normalized to the geometrical mean of a reference gene (LOC_Os07g02340), previously found to show a stable expression pattern across biotic and abiotic stress (Narsai et al., 2010). The Pfaffl method was used to analyse the qRT-PCR data in Microsoft Excel, and the calculated values were expressed relative to the control.

\subsection{Illumina HiSeq2000 sequencing}

The RNAseq gene expression analysis experiment was designed as a three-factor experiment with eight treatments: (1) $\mathrm{LT}+35^{\circ} \mathrm{C}+\mathrm{Mo}$; (2) $\mathrm{LT}+28^{\circ} \mathrm{C}+\mathrm{Mo}$; (3) $\mathrm{LT}+35^{\circ} \mathrm{C}$; (4) $\mathrm{LT}+28^{\circ} \mathrm{C}$; (5) $\mathrm{CO}+35^{\circ} \mathrm{C}+\mathrm{Mo}$; (6) $\mathrm{CO}+28^{\circ} \mathrm{C}+\mathrm{Mo}$; (7) $\mathrm{CO}+35^{\circ} \mathrm{C}$; (8) $\mathrm{CO}+28^{\circ} \mathrm{C}$. These treatments represent the genetic background (LTH or Co39), temperature $\left(28^{\circ} \mathrm{C}\right.$ and $\left.35^{\circ} \mathrm{C}\right)$ and $M$. oryzae inoculation $(\mathrm{Mo})$. The experiment included three biological replicates. Each sample represented leaf material from five plants. Total RNA was isolated using Trizol reagent (Invitrogen, Carlsbad, CA) according to the manufacturer's instructions. The integrity of each RNA sample obtained was examined by Agilent Lab-on-a-chip technology using the RNA 6000 Nano LabChip kit and a Bioanalyzer 2100 (Agilent Technologies, Palo Alto, CA). 
Two micrograms of total RNA were subjected to library preparation using the 'TruSeq RNA Sample preparation v2 Guide' following the manufacturer's instructions. Libraries were clustered for sequencing using Illumina cBOT Cluster generation system and TrusSeq v3 chemistry. Fifty bp single-end sequencing was

562 performed on the HiSeq2000 using three barcoded libraries per lane.

563

5644.8 Preprocessing, mapping, and analysis of illumina reads and subsequent gene expression data

565

566

567

568

569

570

571

572

573

574

575

576

577

578

579

580

581

582

583

584

585

586

587

588

589

590

591

Sequence images were transformed with Illumina software BaseCaller to bcl files, which were demultiplexed to fastq files with CASAVA v1.8.2 allowing for one mismatch in the indices. Sequences were aligned by Bowtie2 v2.0.2 to the Ensembl cDNA release 16 for Oryza sativa. Subsequently, conversion and sorting of the resulting sam files to sorted bam files was conducted with samtools 0.1 .18 followed by counting the reads to each gene. Genes exceeding 50 counts for at least one sample were filtered, followed by normalization via Trimmed Mean and Median-values. In addition, significant differences in the sequencing depth were normalized by expressing the counts in counts-per-million (CPM) so that the counts for each profile are normalized by the total read count of the profile. Counts were then more naturally compared between profiles. Data was analyzed in the R/Bioconductor environment loading DESeq, lattice, estrogen, gplots and colorRamps, biomaRt packages. Estimation of dispersions and testing for differentially expressed genes based on a $\chi 2$ likelihood ratio test, assuming negative binomial data distribution, were computed via DESeq. Candidate genes were filtered to a minimum of $4 \mathrm{x}$ fold change and FDR-corrected $p$-value $<0.05$. Gene annotation was conducted using Ensembl Biomart via R.

Functional association enrichment analysis was conducted via the $\mathrm{R}$ package goseq. The identification of cis elements was performed using Osiris software (available at http://www.bioinformatics2.wsu.edu/cgibin/Osiris/cgi/home.pl), which searches known cis elements from PLACE - Plant Cis-acting Regulatory DNA Elements (Higo et al., 1999) database. Gene co-expression modules (clusters) were identified using Weighted Gene Co-expression Network Analysis (WGCNA) (see the result section for details).

\section{Acknowledgements}

This work was supported by BMZ funded project "Mitigating the impact of climate change on rice diseases in East Africa". We thank the Microarray and Deep-Sequencing Core Facility of the Developmental Biochemistry University Medical Center Göttingen (UMG) for performing the RNA-seq analysis. In particular, we would like to thank Fabian Ludewig for running the illumina sequencing. Our sincere thanks are expressed to Dagmar Tacke, Marian Süß and Daniel Kretzschmar for their technical support. We thank Dr. Carolee Bull from USDA/ARS for critically reading the manuscript and her helpful comments. 


\section{List of figures and tables}

594 Fig. 1. (A). Disease phenotypes of $M$. oryzae (Mo) on LT and CO at $28^{\circ} \mathrm{C}$ and $35^{\circ} \mathrm{C}$ at 5 dpi (B) Disease progress

595

596

597

598

599

600

601

602

603

604

605

606

607

608

609

610

611

612

613

614

615

616

617

618

619

620

621

622 of M. oryzae on Pi54(CO) and Pi54(LT, and their background parents LTH and Co39 at 28 and $35^{\circ} \mathrm{C}$. Same letters above standard error bars indicate no significant difference. Plants were pre-exposed to $35^{\circ} \mathrm{C}$ and $28^{\circ} \mathrm{C}$ for $7 \mathrm{~d}$ prior to Mo inoculation and all plants were incubated at $28^{\circ} \mathrm{C}$ after Mo inoculation for 24 hours prior to reexposure to $35^{\circ} \mathrm{C}$ and $28^{\circ} \mathrm{C}$.

Fig. 2. Callose deposition visualized by aniline blue staining of epidermal cells 48 hpi. $\mathrm{CO}+35^{\circ} \mathrm{C}+\mathrm{Mo}$ and $\mathrm{LT}+35^{\circ} \mathrm{C}+\mathrm{Mo}$ represent plants grown at $35^{\circ} \mathrm{C}$ for $7 \mathrm{~d}$ before inoculation; $\mathrm{CO}+28^{\circ} \mathrm{C}+\mathrm{Mo}$ and $\mathrm{LT}+28^{\circ} \mathrm{C}+\mathrm{Mo}$ are plants grown at $28^{\circ} \mathrm{C}$ before inoculation. Callose deposits were more pronounced at $35^{\circ} \mathrm{C}$ compared to $28^{\circ} \mathrm{C}$ in both genetic backgrounds. Quantification of callose was performed by determining the percentage of yellow pixels related to total pixels of photographs. Data show means \pm standard deviation. Letters indicate significant differences between treatments in each time point $(\mathrm{p}<0.05$; least-significant difference test). The pictures of callose deposition are presented below the corresponding treatments.

Fig. 3. (A) Hydrogen peroxide $\left(\mathrm{H}_{2} \mathrm{O}_{2}\right)$ quantification in micromoles per gram and (B) POX activity measured in mkatal (kat) per gram, of fresh leaf tissue weight (FW) collected from healthy (Mock), M. oryzae inoculated $\left(28^{\circ} \mathrm{C}+\mathrm{Mo}\right)$, high temperature $\left(35^{\circ} \mathrm{C}\right)$, and high temperature plus $M$. oryzae inoculated $\left(35^{\circ} \mathrm{C}+\mathrm{Mo}\right)$. The samples were taken at 24 and 48 hours post inoculation (hpi). Mock28 and $35^{\circ} \mathrm{C}$ samples were taken at 0 hpi. One katal (kat) corresponds to the quantity of enzyme activity that transforms $1 \mathrm{~mol} \mathrm{~S}^{-1}$ of substrate. Data are presented as mean \pm standard deviation. Different letters denote significant differences at $\mathrm{P} \leq 0.05$.

Fig. 4. (A). Comparison of SA accumulation in $\mathrm{CO}$ and $\mathrm{LT}$ at $28^{\circ}$ and $35^{\circ} \mathrm{C}$ and (B) PAL activity expressed as micromolar change in cinnamic acid per minute and gram of fresh leaf tissue weight (FW) collected from healthy (Mock), M. oryzae inoculated $\left(28^{\circ} \mathrm{C}+\mathrm{Mo}\right)$, high temperature $\left(35^{\circ} \mathrm{C}\right)$, and high temperature plus $M$. oryzae inoculated $\left(35^{\circ} \mathrm{C}+\mathrm{Mo}\right)$. The samples were taken at 24 and $48 \mathrm{~h}$ after inoculation (hpi). Mock and $35^{\circ} \mathrm{C}$, represent mock samples exposed to $28^{\circ} \mathrm{C}$ and $35^{\circ} \mathrm{C}$ without pathogen inoculation. $28^{\circ} \mathrm{C}+\mathrm{Mo}$ and $35^{\circ} \mathrm{C}+\mathrm{Mo}$ represent samples infected with $M$. oryzae at 28 and $35^{\circ} \mathrm{C}$. Samples were analyzed at 24 and 48 hours post inoculation (hpi). Different letters denote significant differences at $\mathrm{P} \leq 0.05$.

Fig. 5. Heatmap showing the gene expression clusters and sample clusters of DEG. Samples represent fresh leaf tissue collected from healthy $\left(\operatorname{Mock} 28^{\circ} \mathrm{C}\right), 7$ day high temperature treatment $\left(\mathrm{CO}+35^{\circ} \mathrm{C}, \mathrm{LT}+35^{\circ} \mathrm{C}\right)$, and $\mathrm{Mo}$ inoculated $\left(\mathrm{LT}+28^{\circ} \mathrm{C}+\mathrm{Mo}, \mathrm{LT}+35^{\circ} \mathrm{C}+\mathrm{Mo}, \mathrm{CO}+28^{\circ} \mathrm{C}+\mathrm{Mo}\right.$ and $\left.\mathrm{CO}+35^{\circ} \mathrm{C}+\mathrm{Mo}\right)$, respectively. The color bar represents the $\log 2$ of fold change values compared to Mock $28^{\circ} \mathrm{C}$, ranging from blue to yellow. 
623 Fig. 6. Significant Gene Ontology (GO) enriched terms from differentially up-regulated genes (fold change 4; 624 FDR, 0.05) in rice plants exposed to $35^{\circ} \mathrm{C}$ for 7 days. Comparison of the two genetic backgrounds: $(\mathrm{A}), \mathrm{CO}+35^{\circ} \mathrm{C}$ 625 and $(\mathrm{B}), \mathrm{LT}+35^{\circ} \mathrm{C}$, respectively.

626 Fig. 7. Correlation matrix of module eigengene values obtained for DEG and treatments based on patterns of 627 their co-expression. Infect represents Mo infection, hitemp; high temperature and genotype; genetic background. 628 Within each cell, upper values are correlation coefficients between module eigengene and the treatments; lower 629 values are the correspondent P-value. Each of the cells was labelled with color that signifies the level of 630 correlation. Red represents strong positive correlation whereas blue represents strong negative correlation.

631 Fig. 8. The effect of temperature on transcript levels of Pi54 in LT and CO. The samples were taken at 24 and 48 632 hours post inoculation (hpi). Mock and high temperature samples were taken at 0 hpi. Data are presented as mean 633 fold increases over control \pm standard deviation. Different letters denote significant differences at $\mathrm{P} \leq 0.05$.

634 Fig. 9. Heatmap view of the previously reported PR genes differentially expressed in the six treatments I; 635 $\mathrm{CO}+35^{\circ} \mathrm{C}$, II; $\mathrm{LT}+35^{\circ} \mathrm{C}$, III; $\mathrm{CO}+28^{\circ} \mathrm{C}+\mathrm{Mo}, \mathrm{IV} ; \mathrm{CO}+35^{\circ} \mathrm{C}+\mathrm{Mo}, \mathrm{V} ; \mathrm{LT}+35^{\circ} \mathrm{C}+\mathrm{Mo}, \mathrm{VI} ; \mathrm{LT}+28^{\circ} \mathrm{C}+\mathrm{Mo}$. Cluster analysis of expression profiles of the 78 genes. Yellow indicates higher expression while blue represents lower expression.

638 Fig. 10. Hypothetical defence responses activated in rice-M. oryzae interaction. Prior to infection, ROS are 639 induced by high temperature. In an attempt to manipulate the plant, the fungus secretes effectors to avoid being detected. The R genes and associated RGAs perceive the signals, amplifying ROS. The resulting ROS serve two functions; ABA associated induction of callose at the site of pathogen entry and neighboring cells; and JA synthesis. JA together with methionine probably regulates biosynthesis and activity of JOMTs, SAMTs and ethylene. SAMTs modulate SA conversion to MeSA while JOMTs modulate JA conversion to a more potent MeJA, which probably complements the triggering of phytoalexins, defensins and PRs. Both MeSA and ethylene mobile signals may prime the neighboring cells defences. Increased expression of negative defence regulators, e.g., Auxins, is counteracted by the activity of OsIAA13, OsGH3s. The red lines indicate the first defence responses that restrict the pathogen. The purple lines indicate the subsequent defences (in the order of 1, 2, 3 and 4) that further restrict and probably kill the pathogen. The blue lines indicate interactions that may be necessary to 650 modify cellular response under stressful conditions for multi-protection. The black lines indicate additional 


\section{References}

Awasthi, R., Bhandari, K., Nayyar, H., 2015. Temperature stress and redox homeostasis in agricultural crops. Front Environ Sci. 3, 1-24.

Banerjee, D., Zhang, X., Bent, A.F., 2001. The leucine-rich repeat domain can determine effective interaction between RPS2 and other host factors in Arabidopsis RPS2-mediated disease resistance. Genetics 158, 439450.

Bokszczanin, K.L., Fragkostefanakis, S., Bostan, H., Bovy, A., Chaturvedi, P., Chiusano, M.L., Firon, N., Iannacone, R., Jegadeesan, S., Klaczynskid, K., Li, H., Mariani, C., Müller, F., Paul, P., Paupiere, M., Pressman, E., Rieu, I., Scharf, K.D., Schleiff, E., Van Heusden, A.W., Vriezen, W., Weckwerth, W., Winter, P., 2013. Perspectives on deciphering mechanisms underlying plant heat stress response and thermotolerance. Front Plant Sci. 4, 315.

Cao Y., Ding X., Cai M., Zhao J., Lin Y., Li X., Xu C., Wang S., 2007. The expression pattern of a rice disease resistance gene Xa3/Xa26 is differentially regulated by the genetic backgrounds and developmental stages that influence its function. Genetics 177, 523-533.

Chen, F., D'Auria, J.C., Tholl, D., Ross, J.R., Gershenzon, J., Noel, J.P., Pichersky, E., 2003. An Arabidopsis thaliana gene for methylsalicylate biosynthesis, identified by a biochemical genomics approach, has a role in defence. Plant J. 36, 577-588.

Fu, D.L., Uauy, C., Distelfeld, A., Blechl, A., Epstein, L., Chen, X., Sela, H., Fahima, T., Dubcovsky, J. 2009. A Kinase-START Gene confers temperature-dependent resistance to wheat stripe rust. Science, 323, 1357-1360.

Gijzen, M., MacGregor, T., Bhattacharyya, M., Buzzell, R., 1996. Temperature induced susceptibility to Phytophthora sojae in soybean isolines carrying different Rps genes. Physiol. Mol. Plant Pathol. 48, $209-215$.

Gupta, S.K., Rai, A.K., Kanwar, S.S., Chand, D., Singh, N.K., Sharma, T.R., 2012. The single functional blast resistance gene Pi54 activates a complex defence mechanism in rice. J Exp. Bot. 63, 757-772.

Hao, P., Liu, C., Wang, Y., Chen, R., Tang, M., Du, B., Zhu, L., He, G., 2008. Herbivore-induced callose deposition on the sieve plates of rice: an important mechanism for host resistance.Plant Physiol. 146, 18101820.

Harder, D.E., Samborski, D.J., Rohringer, R., Rimmer, S., Kim, W., Chong, J., 1979. Electron microscopy of susceptible and resistant near-isogenic (sr6/sr6) lines of wheat infected by Puccinia graminis tritici. III. Ultrastructure of incompatible reactions. Can. J. Bot. 57, 2626-2634.

Jennings, C., West, J., Waine, C., Craik, D. and Anderson, M., 2001. Biosynthesis and insecticidal properties of plant cyclotides: The cyclic knotted proteins from Oldenlandia affinis. Proc. Natl. Acad. Sci. USA. 98, 1061410619. 
684

685

686

687

688

689

690

691

692

693

694

695

696

697

698

699

700

701

702

703

704

705

706

707

708

709

710

711

712

713

714

715

Jiang, N., Li, Z., Wu, J., Wang, Y., Wu, L., Wang, S., Wang, D., Wen ,T., Liang, Y., Sun, P., Liu, J., Dai, L., Wang, Z., Wang, C., Luo, M., Liu, X., Wang, G.L., 2012b. Molecular mapping of the Pi2/9allelic gene Pi22 conferring broad-spectrum resistance to Magnaporthe oryzae in the rice cultivar Jefferson. Rice 5, 29.

Jorda, L., Vera, P., 2000. Local and systemic induction of two defence-related subtilisin-like protease promoters in transgenic Arabidopsis plants. Luciferin induction of PR gene expression. Plant Physiol. 124, 1049-1057.

Jung, H.W., Tschaplinski, T.J., Wang, L., Glazebrook, J., Greenberg, J.T., 2009. Priming in systemic plant immunity. Science 324, 89-91

Kamble, A., Bhargava, S., 2007. ß-aminobutyric acid-induced resistance in Brassica juncea against the necrotrophic pathogen Alternaria brassicae. J. Phytopathol. 155, 152-158.

Kawano, Y., Shimamoto, K., 2013. Early signaling network in rice PRR-mediated and R-mediated immunity. Curr. Opin. Plant Biol. 16, 496-504.

Kazan, K., Manners, J.M., 2008. Jasmonate signaling: Toward an integrated view. Plant Physiol. 146, 1459-1468.

Király, L., Hafez, Y.M., Fodor, J., Király, Z., 2008. Suppression of tobacco mosaic virus-induced hypersensitive-type necrotization in tobacco at high temperature is associated with downregulation of NADPH oxidase and superoxide and stimulation of dehydroascorbate reductase. J Gen Virol 89, 799-808.

Liu, G., Lu, G., Zeng, L., Wang, G.L., 2002. Two broad-spectrum blast resistance genes, $P i 9(t)$ andPi2(t), are physically linked on rice chromosome 6. Mol Genet Genomics. 267, 472-480.

Luna, E., Pastor, V., Robert, J., Flors, V., Mauch-Mani, B., Ton, J., 2011. Callose deposition: a multifaceted plant defence response. Mol Plant-Microbe Interact. 24, 183-193.

Meiri, D., Breiman, A., 2009. Arabidopsis ROF1 (FKBP62) modulates thermotolerance by interacting with HSP90.1 and affecting the accumulation of HsfA2-regulated sHSPs. The Plant Journal 59, 387-399.

Narsai, R., Wang, C., Chen, J., Wu, J., Shou, H., Whelan, J., 2013. Antagonistic, overlapping and distinct responses to biotic stress in rice (Oryza sativa) and interactions with abiotic stress. BMC Genomics. 14, 93.

Narsai, R., Ivanova, A., Ng, S., Whelan, J., 2010. Defining reference genes in Oryza sativa using organ, development, biotic and abiotic transcriptome datasets. BMC Plant Biol. 10, 56.

Negeri, A., Wang, G-F., Benavente, L., Kibiti, C.M., Chaikam, V., Johal, G., Balint-Kurti, P., 2013. Characterization of temperature and light effects on the defence response phenotypes associated with the maize Rp1-D21 autoactive resistance gene. BMC Plant Biol. 13, 106.

Nguyen, D., Rieu, I., Mariani, C., van Dam, N.M., 2016. How plants handle multiple stresses: hormonal interactions underlying responses to abiotic stress and insect herbivory. Plant Molecular Biology 91, 727-740.

Nguyen, Q.B., Itoh, K., Van Vu, B., Tosa, Y., Nakayashiki, H., 2011. Simultaneous silencing of endo- $\beta-1,4$ xylanase genes reveals their roles in the virulence of Magnaporthe oryzae. Mol Microbiol 81, 1008-1019. 
Onaga, G., Asea, G., 2016. Occurrence of rice blast (Magnaporthe oryzae) and identification of potential resistance sources in Uganda. Crop Protection 80, 65-72.

Onaga, G., Wydra, K.D., Koopmann, B., Séré, Y., von Tiedemann, A., 2016. Elevated temperature increases in planta expression levels of virulence related genes in Magnaporthe oryzae and compromises resistance in Oryza sativa cv. Nipponbare. Functional Plant Biology (In press).

Park, H.L., Lee, S.W., Jung, K.H., Hahn, T.R. and Cho, M.H., 2013. Transcriptomic analysis of UV-treated rice leaves reveals UV-induced phytoalexin biosynthetic pathways and their regulatory networks in rice. Phytochemistry 96, 57-71.

Park, S.W., Kaimoyo, E., Kumar, D., Mosher, S., Klessig, D.F., 2007. Methyl salicylate is a critical mobile signal for plant systemic acquired resistance. Science 318, 113-116.

Palloix, A., Ayme, V., Moury, B., 2009. Durability of plant major resistance genes to pathogens depends on the genetic background, experimental evidence and consequences for breeding strategies. New Phytol. 183, 190199.

Rivas-San, V.M., Plasencia, J., 2011. Salicylic acid beyond defence: its role in plant growth and development. J. Exp. Bot. 62, 3321-3338.

Seo, S., Mitsuhara, I., Feng, J., Iwai, T., Hasegawa, M., Ohashi, Y., 2011. Cyanide, a co-product of plant hormone ethylene biosynthesis, contributes to the resistance of rice to blast fungus. Plant Physiol. 155, 502-514.

Shimizu, T., Lin, F., Hasegawa, M., Okada, K., Nojiri, H., Yamane, H., 2012. Phytoalexin Sakuranetin in Rice Enzyme in Biosynthesis of Flavonoid Naringenin 7- O-Methyltransferase, a Key Enzyme in Biosynthesis of Flavonoid Phytoalexin Sakuranetin in Rice. J. Biol. Chem. 287, 19315-19325.

Shumilina, D., Krämer, R., Klocke, E., Dzhavakhiya, V., 2006. MF3 (peptidylprolyl cis-trans isomerase of FKBP type from Pseudomonas fl uorescens) - an elicitor of non-specifi c plant resistance against pathogens. Phytopathologia Polonica 41, 39-49.

Sun, X., Y. Cao, Z. Yang, C. Xu, X. Lie et al., 2004. Xa26, a gene conferring resistance toXanthomonas oryzae pv. oryzae in rice, encodes an LRR receptor kinase-like protein. Plant J. 37, 517-527.

Suzuki, N., Bajad, S., Shuman, J., Shulaev, V., Mittler, R., 2008. The transcriptional co-activator MBF1c is a key regulator of thermotolerance in Arabidopsis thaliana. J. Biol. Chem. 283, 9269-9275.

Suzuki, N., Bajad, S., Shuman, J., Shulaev, V. and Mittler, R., 2008. The transcriptional co-activator MBF1c is a key regulator of thermotolerance in Arabidopsis thaliana. J. Biol. Chem 283, 9269-9275.

Takagi, H., Ishiga, Y., Watanabe, S., Konishi, T., Egusa, M., Akiyoshi, N., Matsuura, T., Mori, IC., Hirayama, T., Kaminaka, H., Shimada, H., Sakamoto, A., 2016. Allantoin, a stress-related purine metabolite, can activate jasmonate signaling in a MYC2-regulated and abscisic acid-dependent manner. Journal of Experimental Botany 67, 2519-2532. 
749 Webb, K.M., Ona, I., Bai, J., Garrett, K.A., Mew, T., Cruz, V., Leach, J.E., 2011. A benefit of high temperature: 750 increased effectiveness of a rice bacterial blight disease resistance gene. New Physiol. 185, 568-576.

751 Whitham, S., McCormick, S., Baker, B., 1996. The N gene of tobacco confers resistance to Tobacco mosaic virus 752 in transgenic tomato. Proc. Natl. Acad. Sci. U.S.A. 93, 8776-8781.

753 Xiao, S., Brown, S., Patrick, E., Brearley, C., Turner, J.G., 2003. Enhanced transcription of the Arabidopsis 754 disease resistance genes RPW8.1 and RPW8.2 via a salicylic acid-dependent amplification circuit is required 755 for hypersensitive cell death. Plant Cell 15, 33-45.

756 Xue, $\quad$ M., Yang, $\quad$ J., Li, $\quad$ Z., Hu, $\quad$ S., Yao, $\quad$ N., Dean, $\quad$ R.A., Zhao, $\quad$ W., Shen, $\quad$ M., Zhang, $\quad$ H., Li, 757 C. et al., 2012. Comparative analysis of the genomes of two field isolates of the rice blast fungus Magnaporthe $758 \quad$ oryzae. PLoS Genetics 8, e1002869.

759 Yang, S.H., Hua, J., 2004. A haplotype-specific resistance gene regulated by BONZAI1 mediates temperature760 dependent growth control in Arabidopsis. Plant Cell 16, 1060-1071.

761 Zhang, S., Wang, L., Wu, W., He, L., Yang, X., Pan, Q., 2015. Function and evolution of Magnaporthe oryzae 762 avirulence gene AvrPib responding to the rice blast resistance gene Pib. Sci. Rep. 5, 11642. 

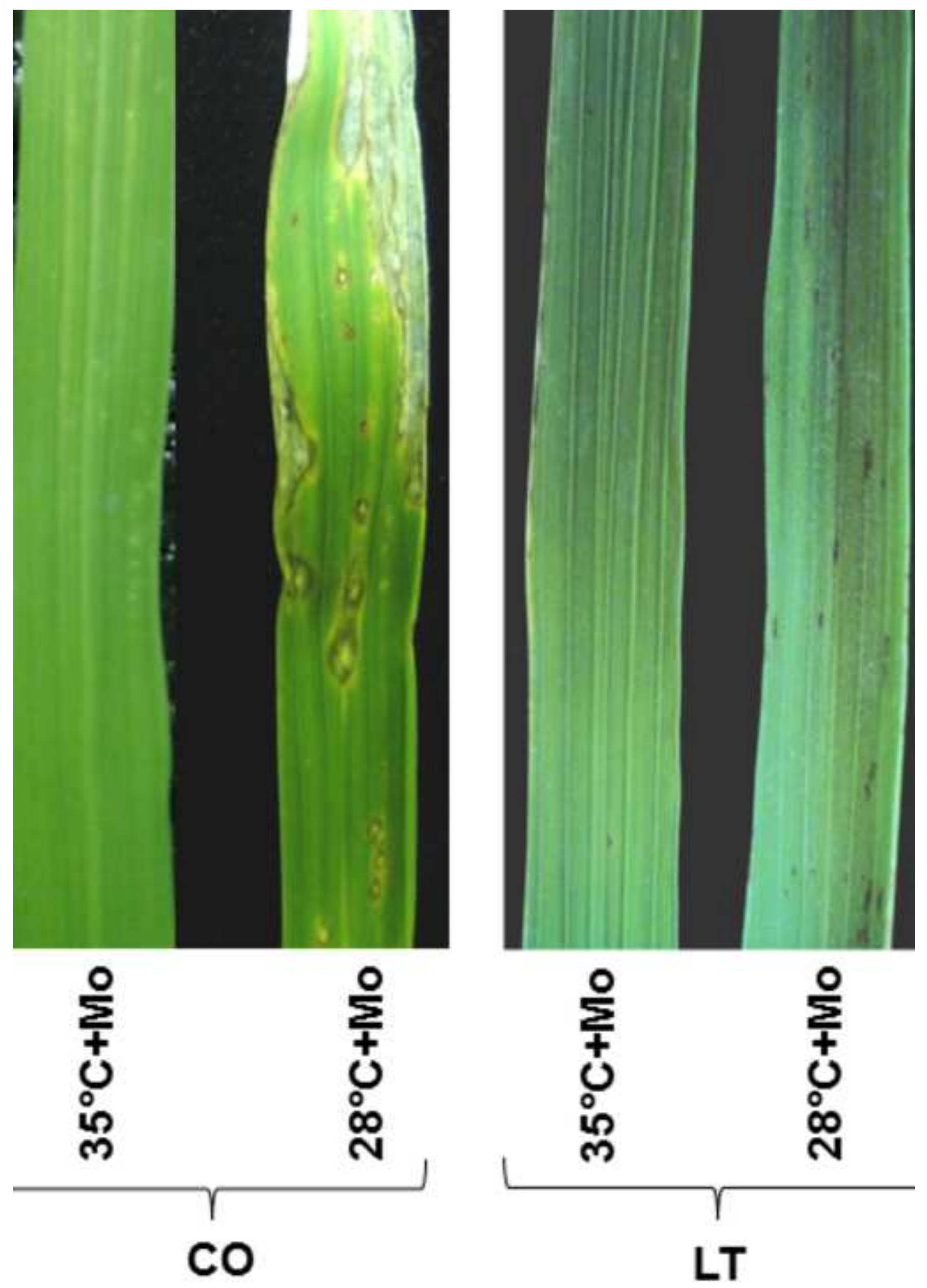


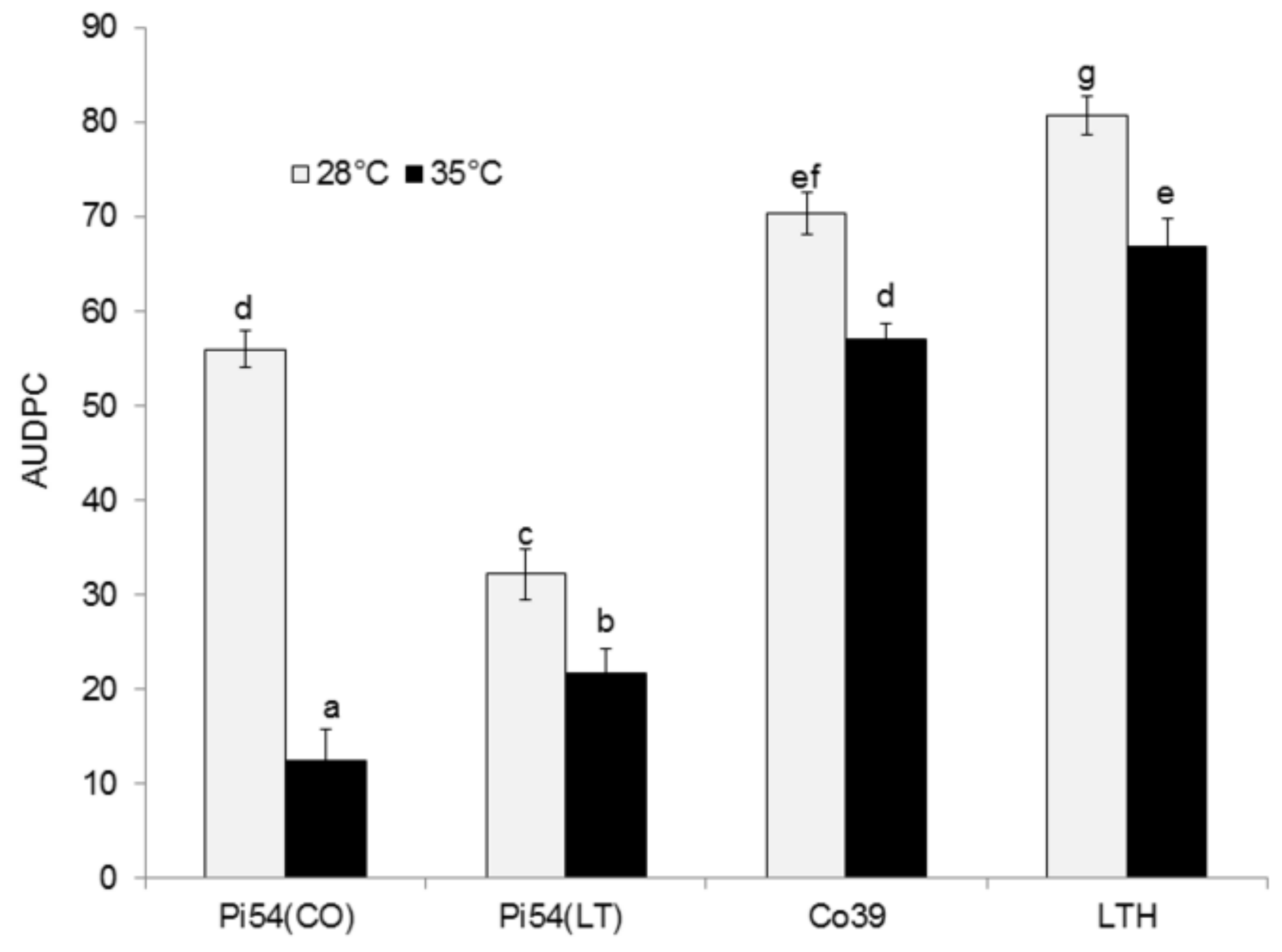

Genotypes 


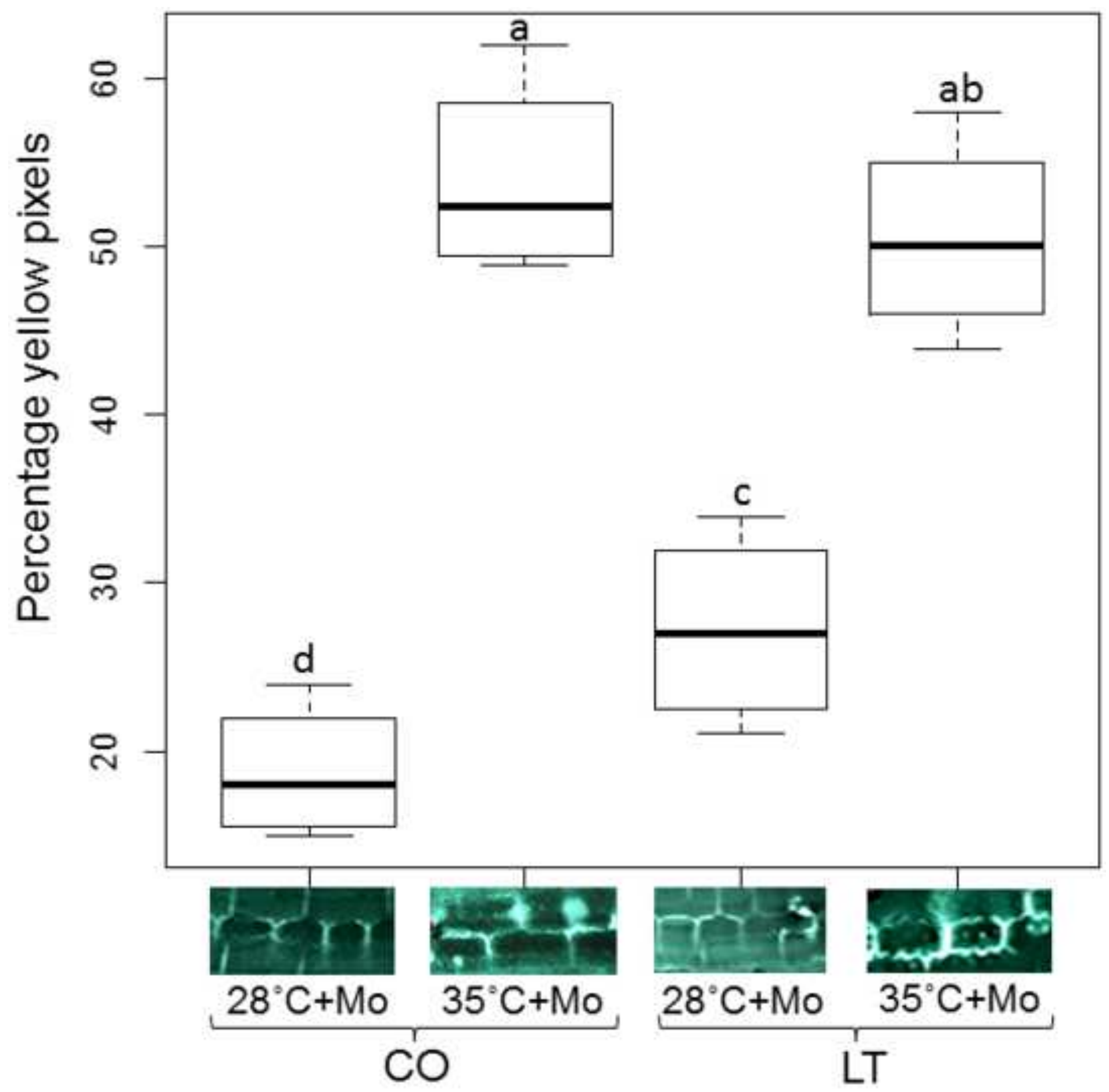




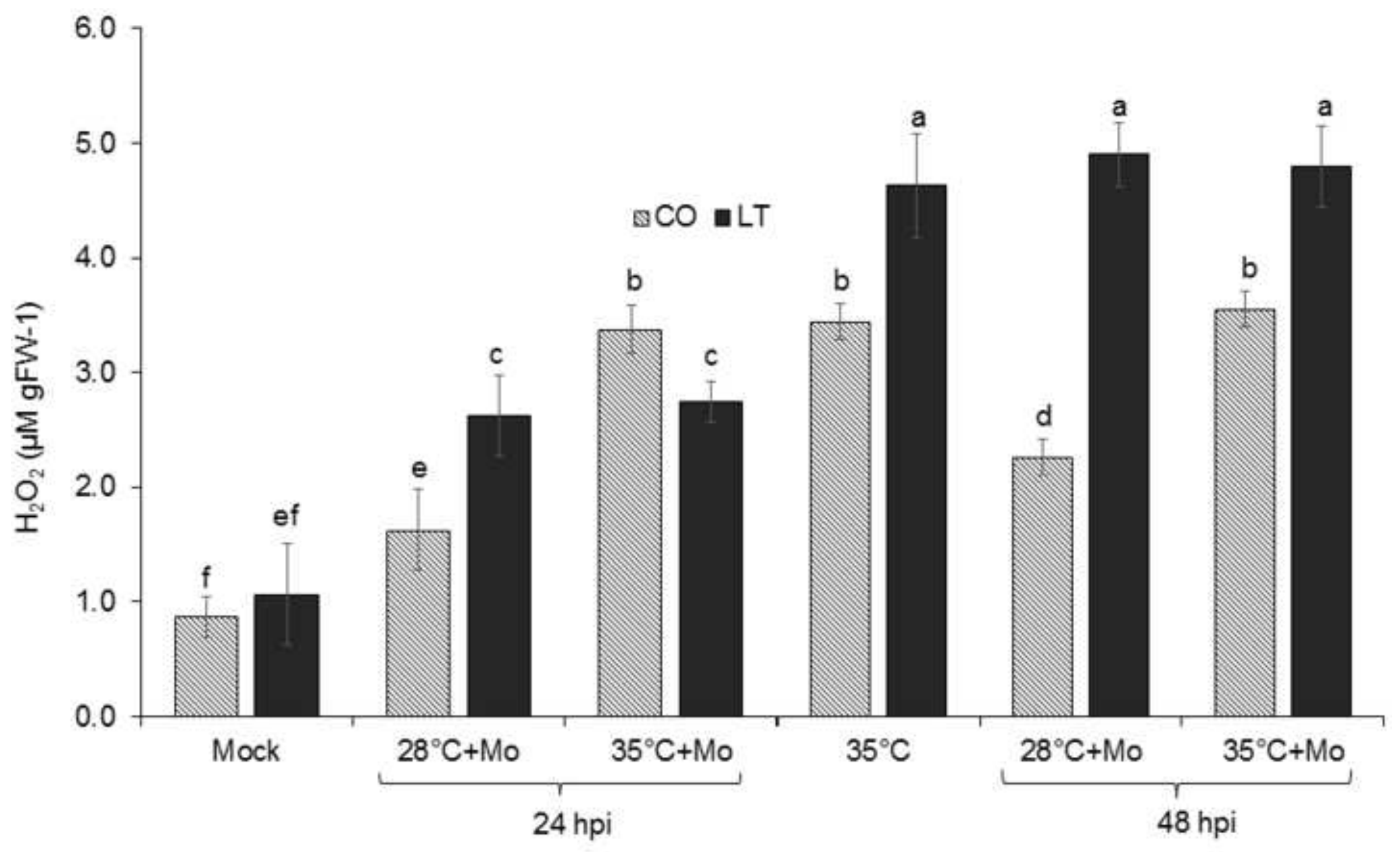




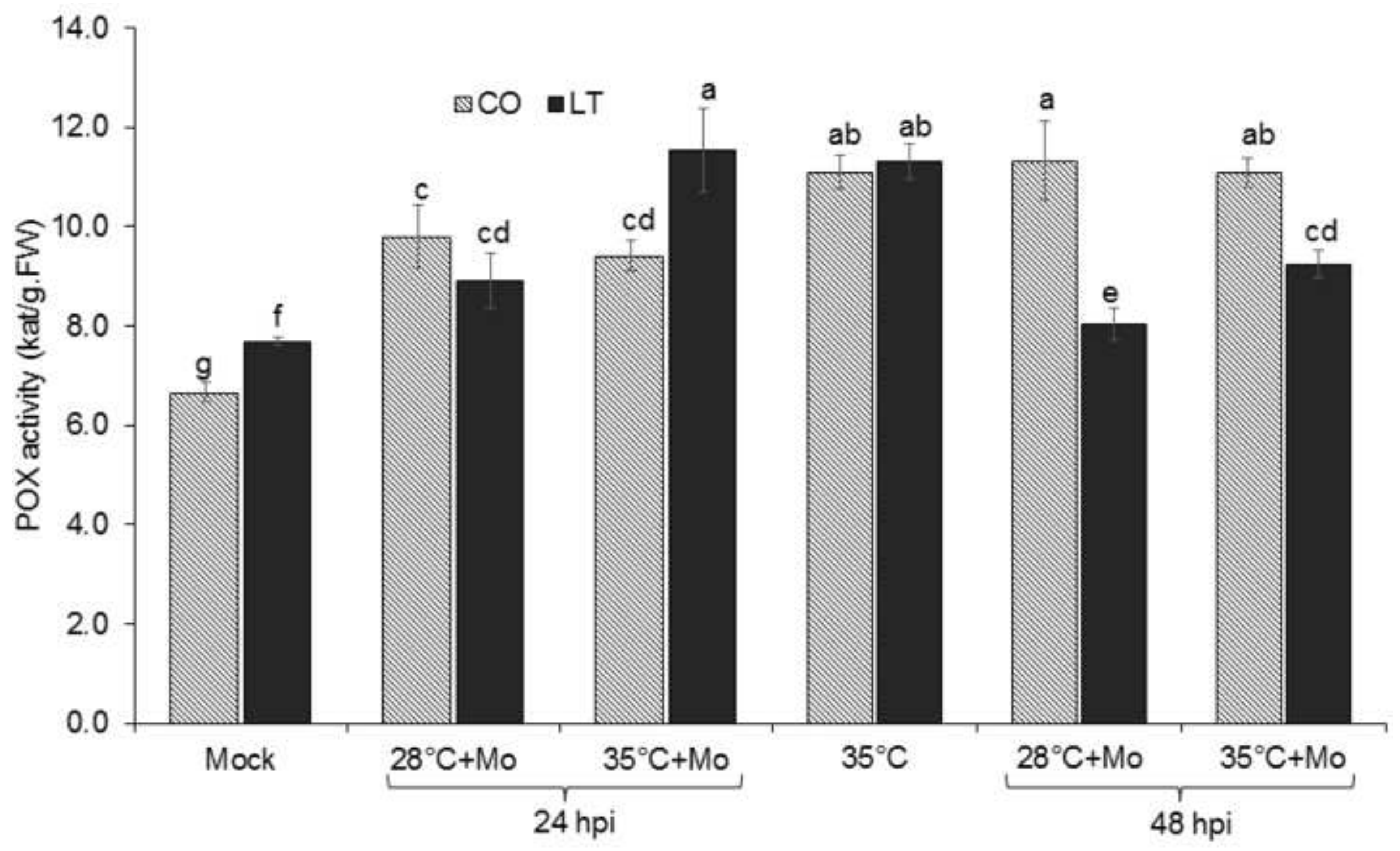




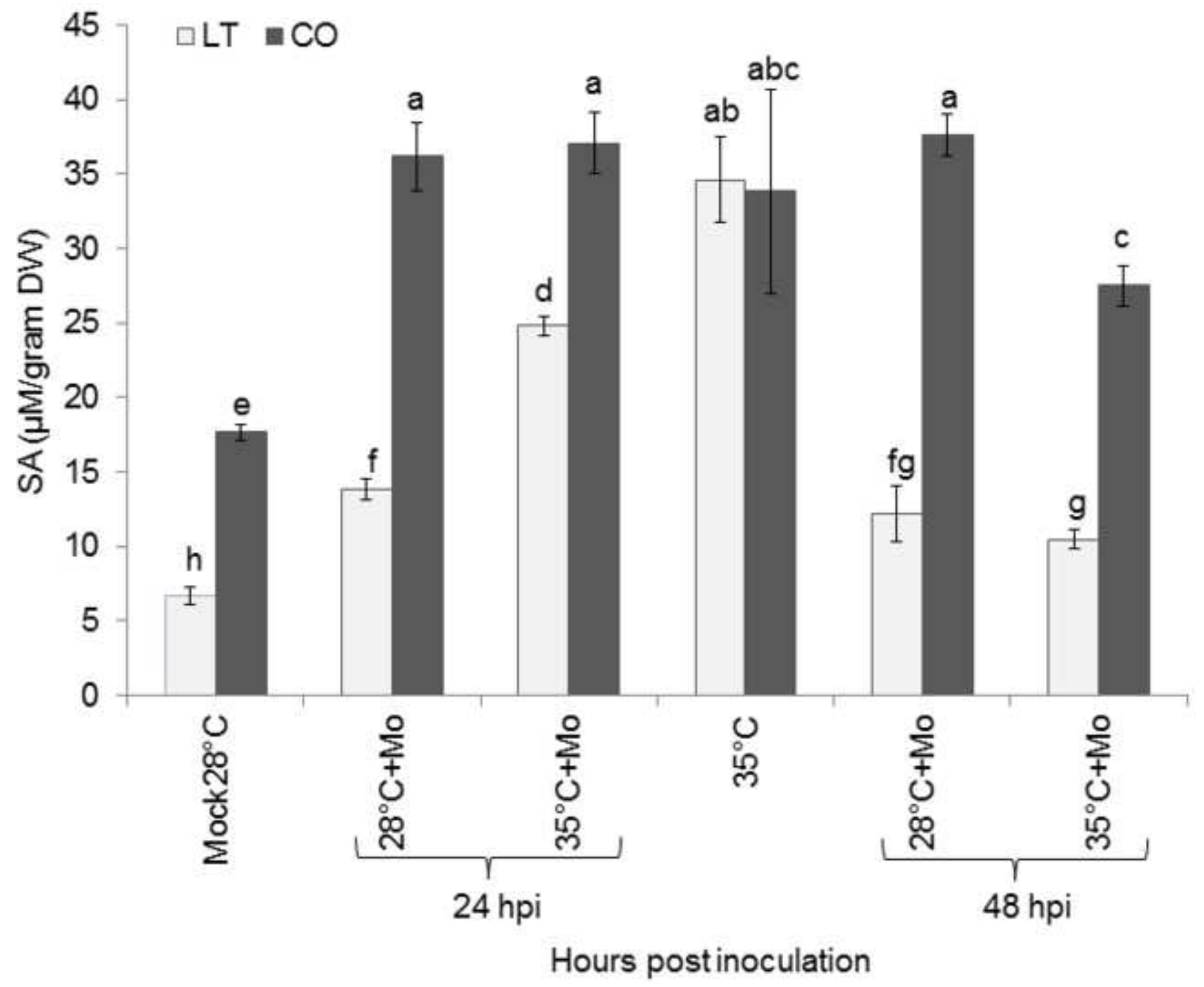




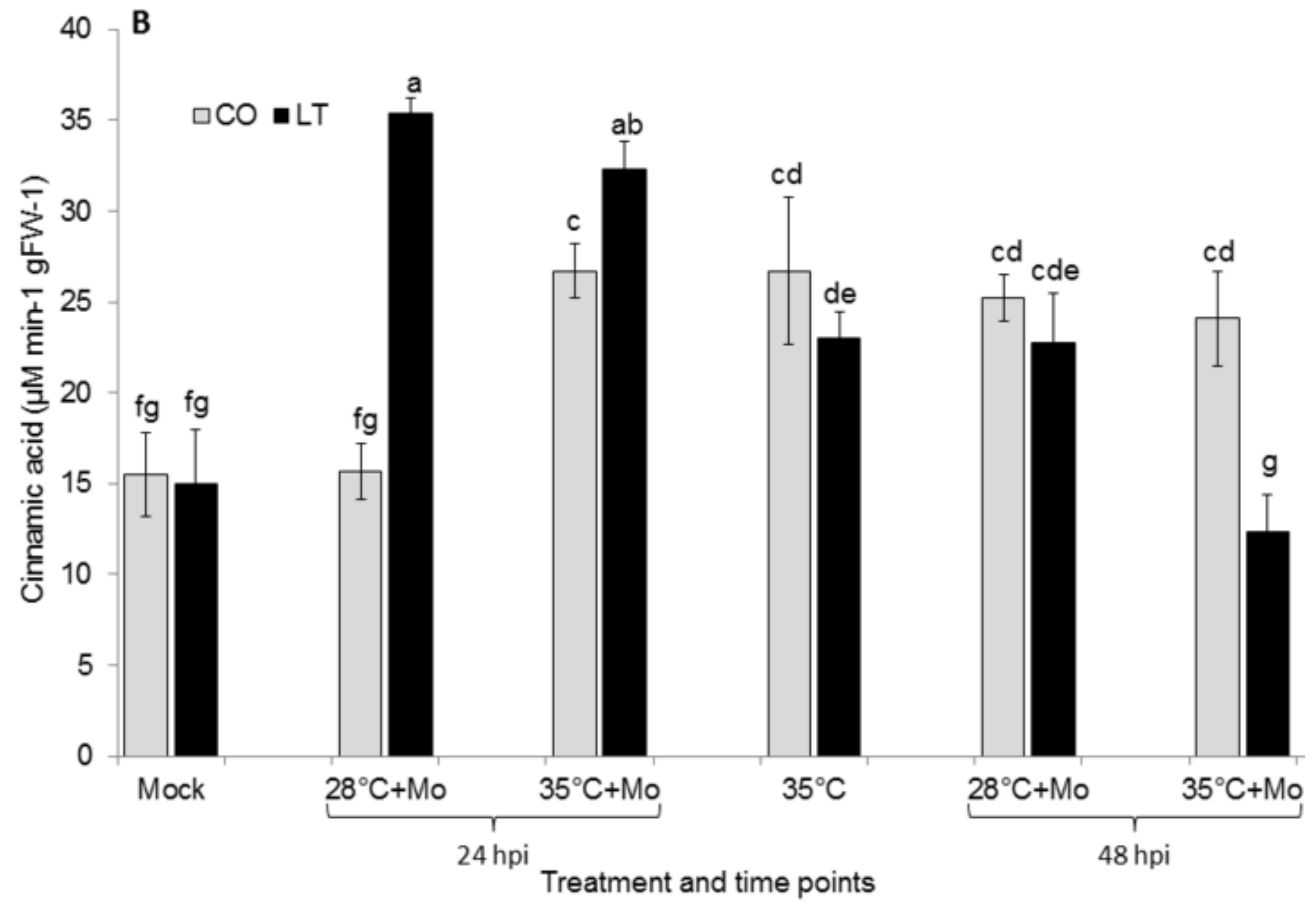


Color Key
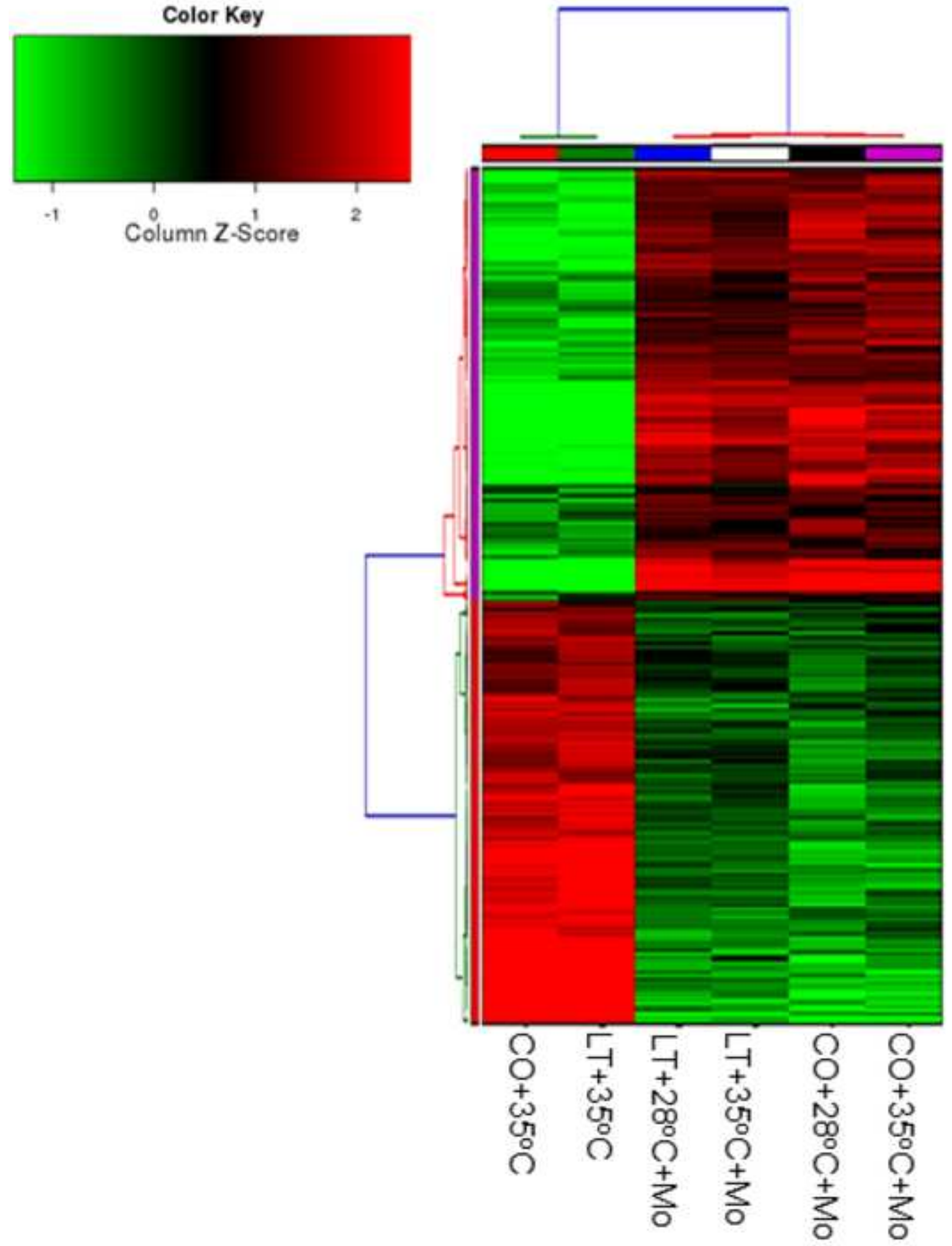


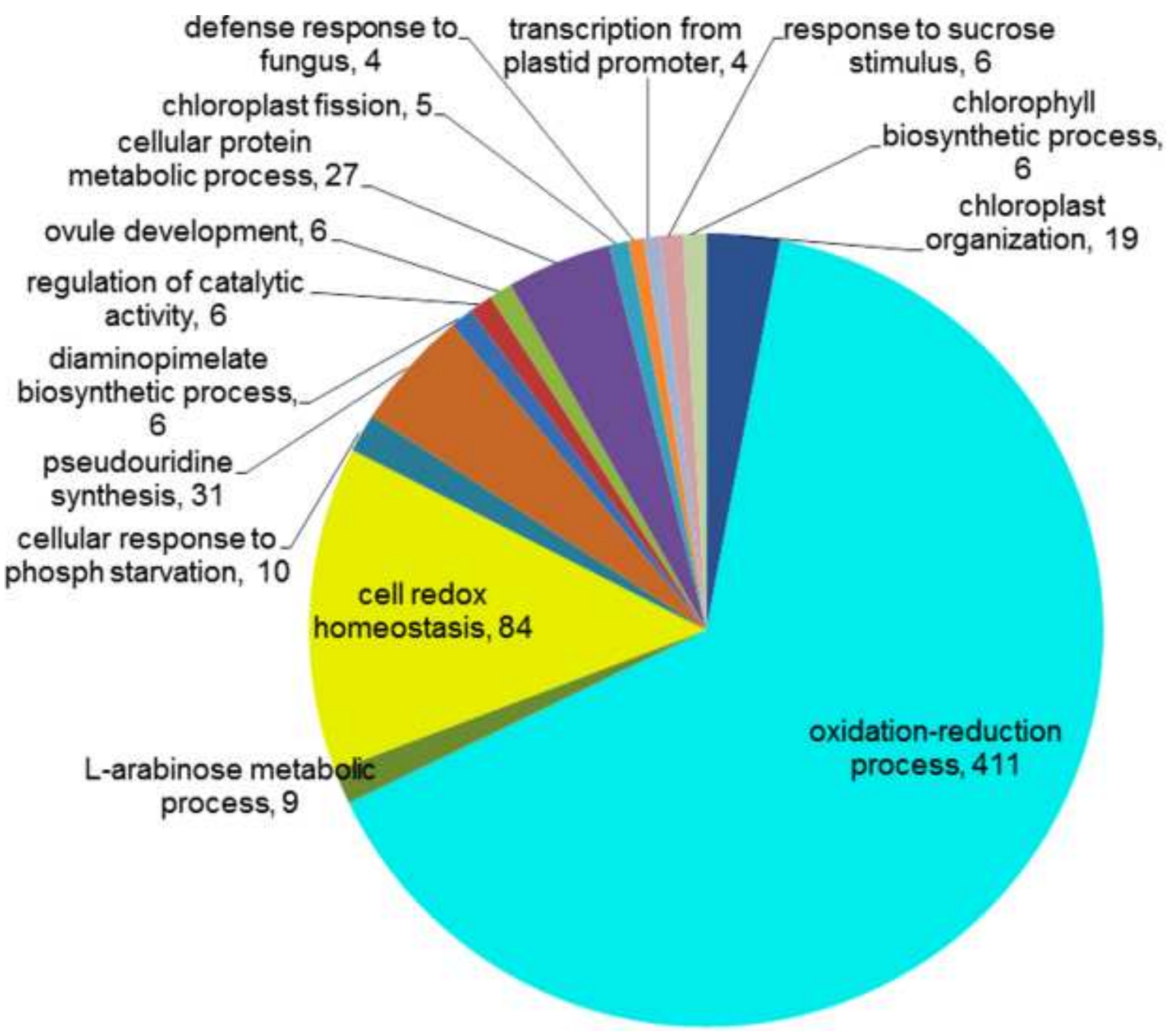




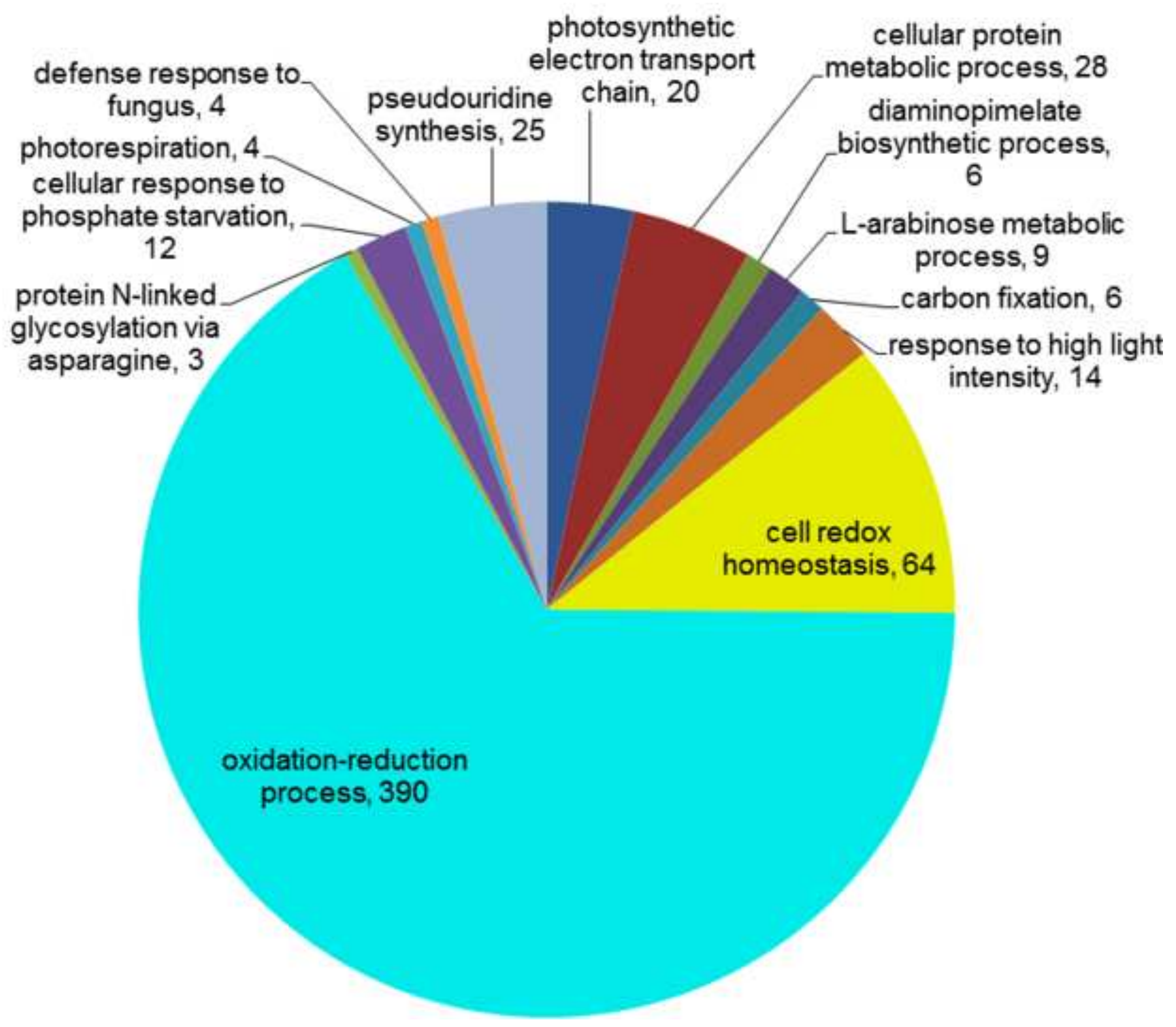




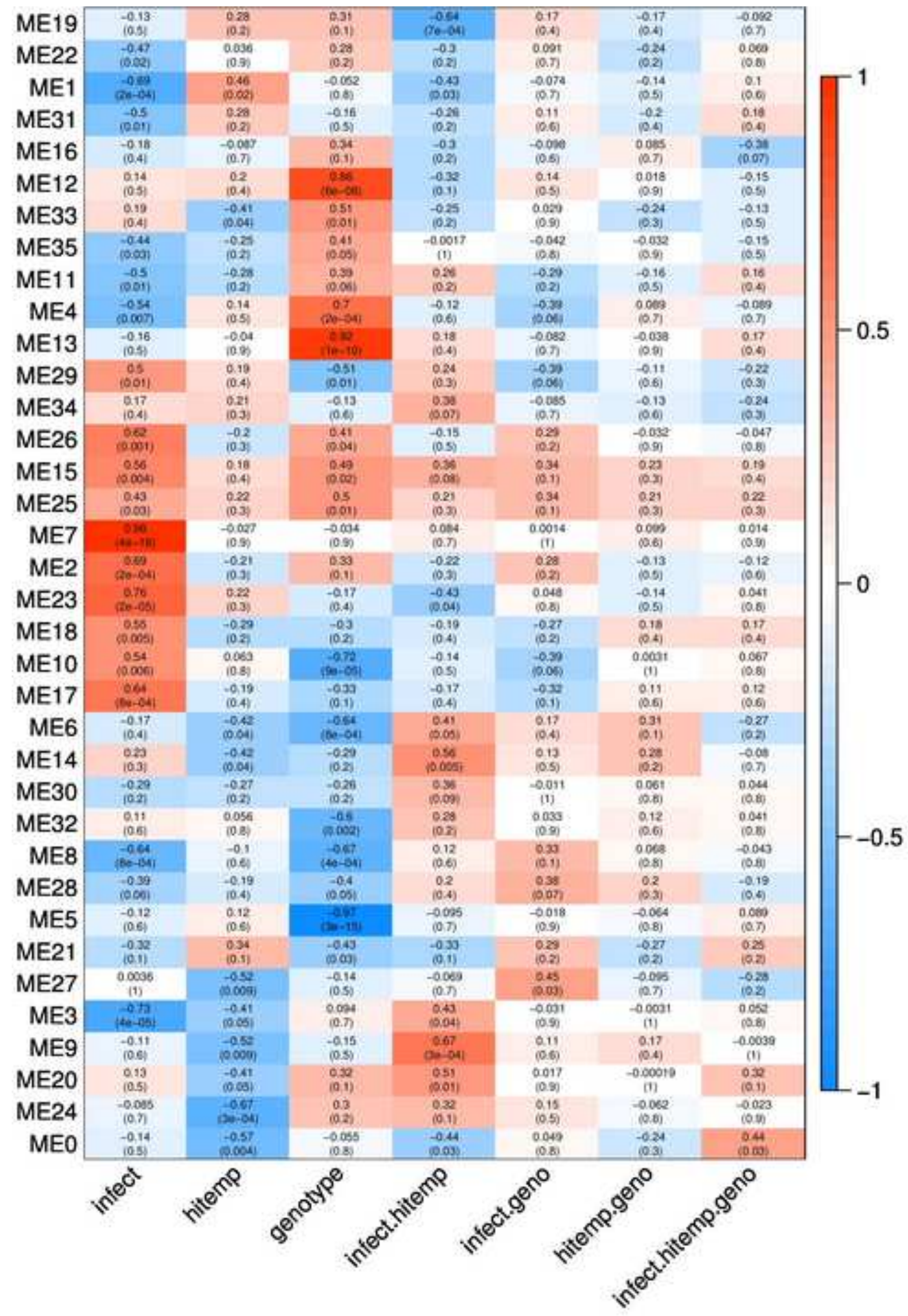




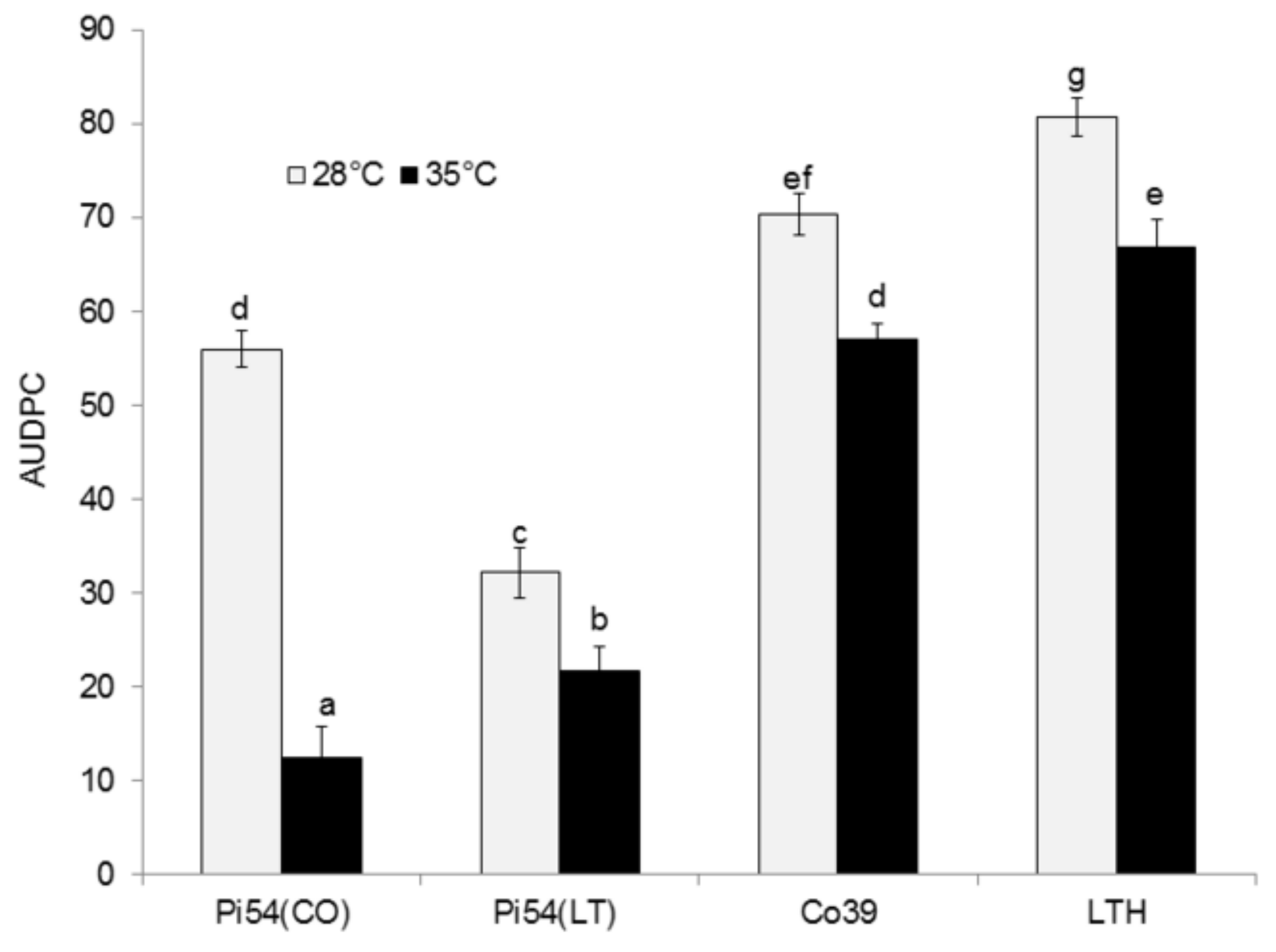

Genotypes 

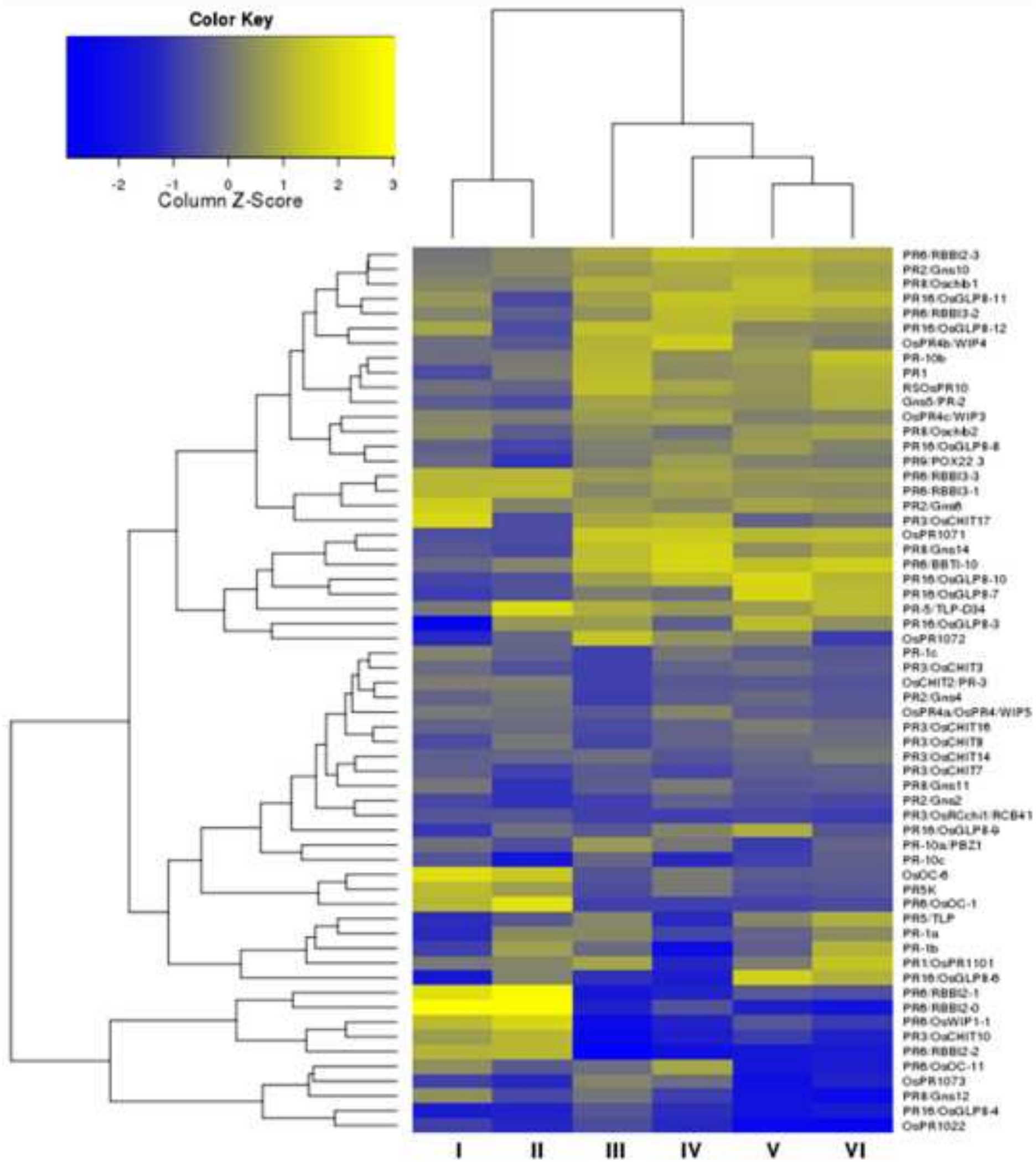


\section{High temperature}

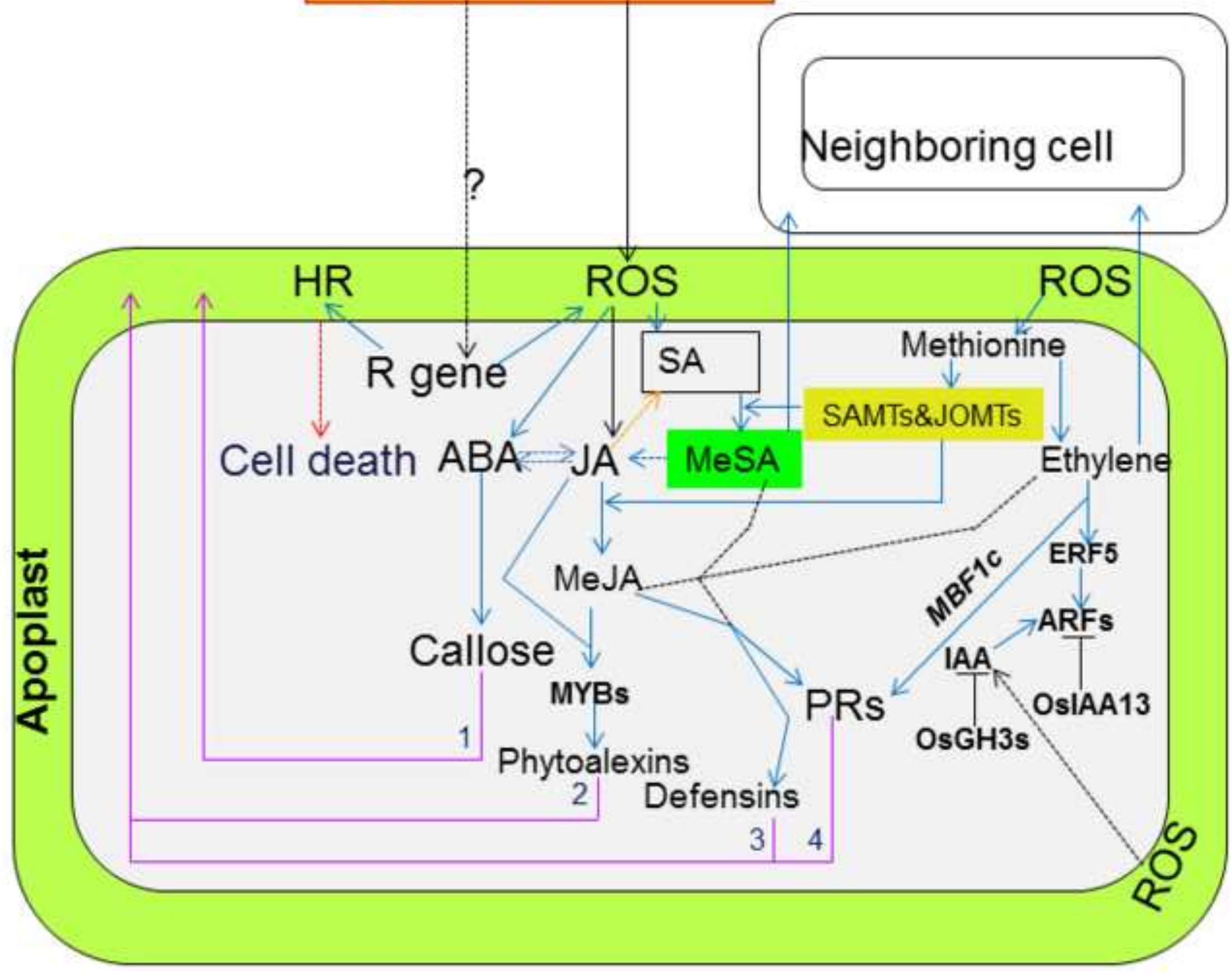

